\title{
Assessing experimental visceral pain in dairy cattle: A pilot, prospective, blinded, randomized, and controlled study focusing on spinal pain proteomics
}

\author{
P. Rialland, ${ }^{*}$ C. Otis, ${ }^{*}$ M.-L. de Courval, ${ }^{*}$ P.-Y. Mulon,† D. Harvey,† S. Bichot, ${ }^{\star}$ D. Gauvin, ${ }^{*}$ A. Livingston,‡ \\ F. Beaudry, ${ }^{*}$ P. Hélie,§ D. Frank, $†$ J. R. E. del Castillo, ${ }^{\star}$ and E. Troncy ${ }^{\star 1}$ \\ ${ }^{*}$ Quebec Research Group in Animal Pharmacology (GREPAQ), Department of Veterinary Biomedical Sciences, \\ Faculté de Médecine Vétérinaire - Université de Montréal, Saint-Hyacinthe, QC, J2S 7C6, Canada \\ †Department of Clinical Sciences, Faculté de Médecine Vétérinaire - Université de Montréal, Saint-Hyacinthe, QC, J2S 7C6, Canada \\ $\ddagger$ Western College of Veterinary Medicine, University of Saskatchewan, Saskatoon, SK, S7N 5B4, Canada \\ §Department of Pathology and Microbiology, Faculté de Médecine Vétérinaire, Université de Montréal, Saint-Hyacinthe, QC, J2S 7C6, Canada
}

\begin{abstract}
Few studies have verified the validity of behavioral and physiological methods of pain assessment in cattle. This prospective, blinded, randomized controlled experimental study aimed to validate different methods of pain assessment during acute and chronic (up to $21 \mathrm{~d}$ postintervention) conditions in dairy cattle, in response to 3 analgesic treatments for traumatic reticuloperitonitis. Cerebrospinal fluid (CSF) biomarkers and mechanical sensitization were measured as indicators of centralized pain. Proteomics in the CSF were examined to detect specific (to pain intensity) and sensitive (responsive to analgesia) markers. Recordings of spontaneous behavior with video analysis, telemetered motor activity, pain scales, electrodermal activity, and plasma cortisol concentration were quantified at regular intervals. Cows were assigned to group $1(\mathrm{n}=$ 4 , standard control receiving aspirin), group 2 ( $\mathrm{n}=$ 5 , test group receiving preemptive tolfenamic acid), or group $3(\mathrm{n}=3$, positive control receiving preemptive multimodal analgesia composed of epidural morphine, plus tolfenamic acid and butorphanol). Rescue analgesia was administered as needed. Generalized estimating equations tested group differences and the influence of rescue analgesia on the measurements. All 3 groups demonstrated a long-term decrease in a CSF protein identified as transthyretin. The decrease in transthyretin expression inversely correlated with the expected level of analgesia (group $1<2<3$ ). Moreover, in group 1, CSF noradrenaline decreased long term, cows were hypersensitive to mechanical stimulation, and they demonstrated signs of discomfort with higher motor activity and "agitation while lying" recorded from video analysis. Decreased "feeding behavior," observer-
\end{abstract}

Received June 13, 2013.

Accepted December 21, 2013

${ }^{1}$ Corresponding author: eric.troncy@umontreal.ca reported pain scales, electrodermal activity, and plasma cortisol concentration were inconsistent to differentiate pain intensity between groups. In summary, changes in CSF biomarkers and mechanical sensitization reflected modulation of central pain in dairy cows. The spontaneous behavior "agitation while lying" was the only behavioral outcome validated for assessing acute and chronic pain in this visceral pain model.

Key words: pain metrology, animal behavior, central sensitization, preemptive multimodal analgesia

\section{INTRODUCTION}

Visceral pain is considered one of the most painful clinical conditions in adult cattle (Huxley and Whay, 2006; Laven et al., 2009). In addition, knowledge relevant to chronic pain mechanisms is lacking in dairy cattle (Walker et al., 2011). It is very difficult to develop new analgesic treatments for cows in the absence of a validated method of pain assessment that integrates the basic scientific knowledge of central pain mechanisms in this species. The overall challenge is therefore to investigate which pain mechanism(s) is(are) associated with a specific clinical condition, and in particular to relate it(them) to signs and pain symptoms in cattle. This is even more crucial for visceral pain, such as that caused by traumatic reticuloperitonitis (TRP). The signs of naturally occurring TRP disease are consistent with localized peritonitis and include anorexia, fever, tachypnea, and an arched stance with abducted elbows (indicating cranial abdominal pain). Acute and chronic TRP has never been investigated, to the best of our knowledge, in a bovine pain study. Therefore, this study represents an original opportunity to establish the validity of usual methods of bovine pain assessment in this specific visceral pain model.

Pain evaluation in cattle has generally been studied in the context of routine livestock husbandry and surgical procedures and clinical disease states. For example, 
husbandry procedures (Molony et al., 1995; Stafford and Mellor, 2005), orthopedic lameness (Huxley and Whay, 2006; Laven et al., 2009), inflammatory diseases (Kemp et al., 2008; Rasmussen et al., 2011), and abdominal procedures (Mialon et al., 2012) induce pain of variable intensity. Accordingly, physiologic measures related to the sympathetic system, such as hypothalamic-pituitary-adrenal (HPA) activity (reflected by heart rate as well as plasma cortisol and catecholamine alterations), behavioral (spontaneous and nocifensive) responses, and general bodily functions (such as food intake, weight gain, milk balance, or energy balance) have been used to assess pain in cattle. In general, only the methods comprising dosage of cortisol and objective measurements of behavioral changes have led to the approval of analgesic drugs in cattle, such as lidocaine, xylazine, and many nonsteroidal antiinflammatory drugs (NSAID). Therefore, determination of the clinical validity of these models has largely been based on the pharmacological responsiveness of the aforementioned analgesic drugs (Stafford and Mellor, 2005; Baldridge et al., 2011). Nevertheless, stress and handling of cattle might be major confounding factors in the evaluation of pain and analgesic responses (Stilwell et al., 2010; Baldridge et al., 2011; Mialon et al., 2012), thus decreasing the ability to detect pain, and in consequence the real efficacy of the tested analgesic. Indeed, the interpretation of bovine physiologic and behavioral changes in terms of the individual animal's pain experience is therefore far from straightforward.

With the difficulty faced by veterinarians in appreciating pain mechanisms, proteomic (analysis of proteins) technologies could be helpful to gain insight into pain, proteomics being the link between genes, proteins, and disease. In pathological pain, proteome changes in the spinal cord might reflect corresponding protein regulatory modifications that are involved in the centralized pain sensitization (Kunz et al., 2005). Interestingly, proteomic analysis of cerebrospinal fluid (CSF) has been used to identify biomarkers in human central nervous system disorders (Jahn et al., 2011). Thus, identifying unique patterns of protein expression, or biomarkers, associated with centralized pain sensitization might be a promising area of pain diagnostics in cattle when compared with (or in complement to) the usual behavioral and physiological methods that are not directly linked to the physiological pathways of the cells in the central nervous system. We propose that the identification of CSF proteins in pathological pain conditions may serve as a sensitive and specific method to quantify pain. These methods have not been used in cattle to date, but have the potential for evaluating the neurophysiological changes underlying central pain mechanisms.
The purpose of the present study was to evaluate different methods quantifying pain intensities in cows following TRP induced by visceral surgery. Over a 21-d period, the objective was to estimate the sensitivity (e.g., the ability to predict the responsiveness to analgesics) and specificity (e.g., the ability to detect negative outcomes) of several methods of pain assessment - CSF biomarkers; mechanical pain threshold (MPT); spontaneous behavior assessed using accelerometry and video analysis; observer-reported pain using a visual analog scale (VAS), a veterinarian pain scale (VPS), and a technician pain scale (TPS); and 2 physiological measurements, electrodermal activity (EDA) and plasma cortisol-following surgical induction of TRP in conjunction with treatment with 1 of 3 analgesic protocols (each expected to provide a different level of analgesia). We hypothesized that the TRP surgery used to generate pain would induce significant changes detectable by all methods of pain assessment, the methods being able to distinguish 3 levels in pain intensity (group $1>$ group $2>$ group 3 ) as following: preemptive multimodal (multiple analgesic drug classes and potentially route administration) analgesia (used in group 3) would lead to smaller changes than would preemptive unimodal (antiinflammatory) analgesia (group 2), which, in turn, would lead to smaller changes than those seen with single postoperative aspirin administration (group 1).

\section{MATERIALS AND METHODS}

\section{Animals}

All procedures involving the use of animals were approved by the Institutional Animal Care and Use Committee (RECH-1261), and were consistent with the Canadian Council on Animal Care guidelines for animals' healthcare and management (Olfert et al., 1993). Twelve healthy, lactating Holstein cows [mean (SD)] averaging 4.8 (1.5) yr of age and weighing 654 (79) $\mathrm{kg}$ were selected from the internal livestock of the Faculty of Veterinary Medicine (FMV; Université de Montréal, St-Hyacinthe, QC, Canada) and from surrounding private farms. All cows underwent a thorough clinical examination and serum biochemical and hematological analyses to rule out lameness, mastitis, and the presence of either noninflammatory or inflammatory disease. They were also assessed for pain using a VAS (Laven et al., 2009). The cows underwent an acclimation period of $3 \mathrm{wk}$ before the study at the FMV. They were housed in individual tiestalls (neckbar ties) on dry straw bedding that was changed daily. Room temperature was $23.4(4.0)^{\circ} \mathrm{C}$ and air changes were not controlled. The cows were fed hay ad libitum and a concentrate mix (Synchro 6000 dairy ration 


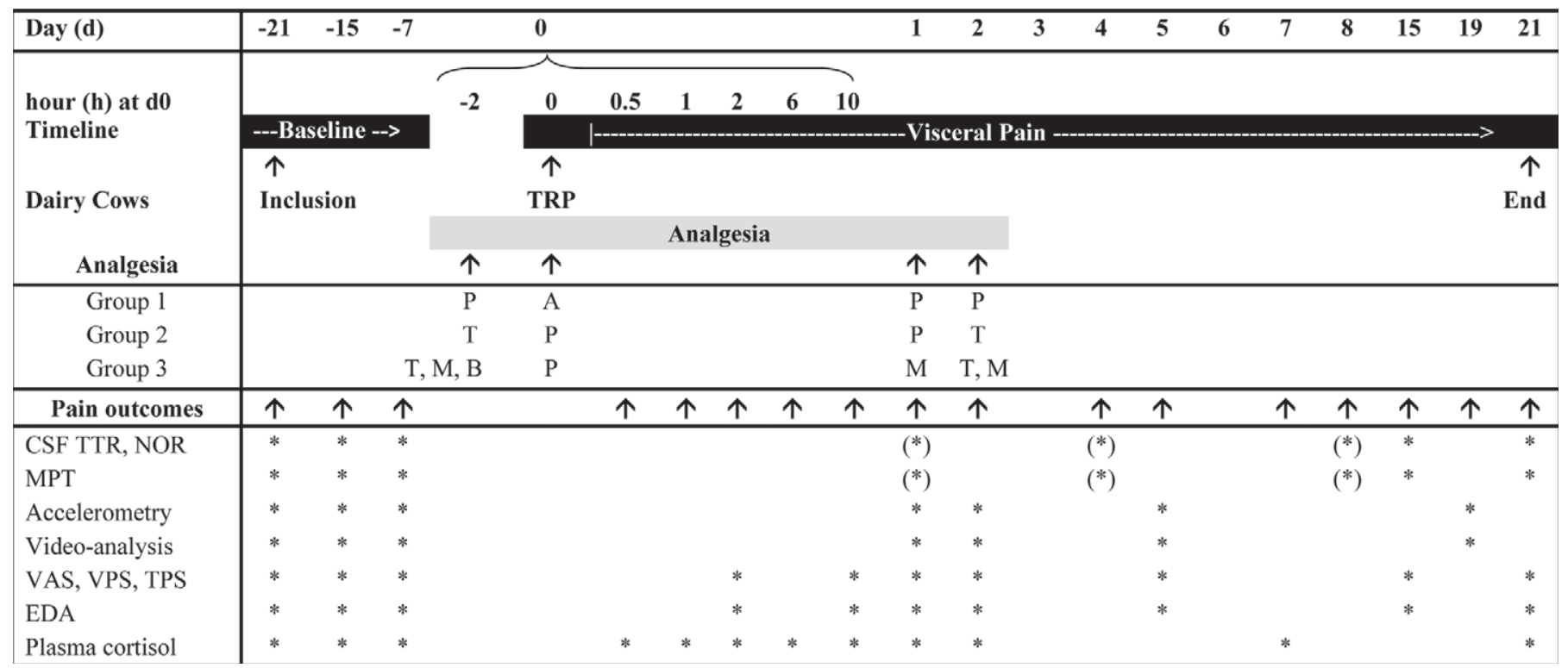

Figure 1. Study design. Timeline shows activities from d -21 through d 21 . TRP $=$ traumatic reticuloperitonitis; CSF TTR, NOR $=$ cerebrospinal fluid transthyretin and noradrenaline; MPT = mechanical pain threshold; VAS = visual analog scale; VPS $=$ veterinarian pain scale; TPS = technician pain scale; EDA = electrodermal activity; ${ }^{*}=$ sampling or recording at the corresponding time; $(*)$ data from d 1 to 8 were pooled for the same pain outcome. Analgesia: A = intrarumenal acetylsalicylic acid at a dose of $50 \mathrm{mg} / \mathrm{kg}$ : $\mathrm{T}=$ tolfenamic acid given intramuscularly at a dose of $2 \mathrm{mg} / \mathrm{kg} ; \mathrm{M}=$ epidural morphine sulfate at a dose of $0.1 \mathrm{mg} / \mathrm{kg} ; \mathrm{B}=$ subcutaneous butorphanol at a dose of 0.1 $\mathrm{mg} / \mathrm{kg} ; \mathrm{P}=$ placebo.

16\%, Co-Op, Montreal, QC, Canada) 3 times a day. The amount of concentrate to be fed to each lactating cow was calculated based on BW (Conseil-Lait software 1996, Valacta, Ste-Anne-de-Bellevue, QC, Canada) and did not exceed $6 \mathrm{~kg} / \mathrm{d}$. Water was supplied ad libitum. The cows were milked twice daily (at 0530 and at 1600 h). Clinical evaluations were performed daily, at the time of milking.

\section{Study Design}

The design was a 2-phase study comprising a 21-d baseline period (measurements at $\mathrm{d}-21, \mathrm{~d}-15$, and $\mathrm{d}-7$ ) followed by surgically induced TRP pain on $\mathrm{d}$ 0 at $\mathrm{h} 0$, followed by a 21-d period of visceral pain follow-up (Figure 1). Data recorded at $\mathrm{d}-7$ were used as baseline values. The CSF sampling, MPT, accelerometry, video analysis, pain scales (VAS, VPS, TPS), EDA, and plasma cortisol were recorded according to the timeframe (Figure 1). For CSF biomarkers and MPT, data from d 1 to 8 were pooled to maximize the power of the analysis in a pilot study and thereafter noted as d 1-8. Accelerometer and video analysis were continuously recorded and analyzed over $24 \mathrm{~h}$ on each day of recording. All observers were blinded to group assignment.

The cows were randomly assigned to 1 of 3 treatment conditions. Group 1 cows $(\mathrm{n}=4)$ were treated with
$50 \mathrm{mg} / \mathrm{kg}$ of intraruminal acetylsalicylic acid (Vetoquinol Canada Inc., Lavaltrie, QC, Canada) at d 0 (h 1). Group 2 cows $(n=5)$ received unimodal analgesia comprising an i.m. injection of $2 \mathrm{mg} / \mathrm{kg}$ tolfenamic acid (Vetoquinol SA, Lure, France), administered $2 \mathrm{~h}$ before surgery on $\mathrm{d} 0(\mathrm{~h}-2)$ and repeated $48 \mathrm{~h}$ later $(\mathrm{d} 2)$. Group 3 cows $(\mathrm{n}=3)$ received preemptive multimodal analgesia that consisted of (1) i.m. tolfenamic acid at a dose of $2 \mathrm{mg} / \mathrm{kg}$ at $\mathrm{h}-2$ and $\mathrm{h} 46$; (2) epidural morphine sulfate at a dose of $0.1 \mathrm{mg} / \mathrm{kg}$ (Laboratoire Chaix et Du Marais, Paris, France) at $\mathrm{h}-2$ and repeated at $\mathrm{h}$ 22 and h $46 ;(3)$ s.c. butorphanol at a dose of $0.1 \mathrm{mg} / \mathrm{kg}$ (Wyeth Animal Health, Guelph, ON, Canada) at h -2 . Placebos in the form of $5 \mathrm{~mL} / 100 \mathrm{~kg}$ of sodium chloride (Baxter Corporation, Toronto, ON, Canada) i.m., 15 $\mathrm{mL}$ of sterile water (Bimeda-MTC Animal Health Inc., Cambridge, ON, Canada) epidurally, $1 \mathrm{~mL} / 100 \mathrm{~kg}$ sodium chloride s.c., and flour powder were administered at $\mathrm{h}-2, \mathrm{~h} 22$, and $\mathrm{h} 46$ in cows that did not receive the corresponding (by dose and route of administration) analgesic drugs.

\section{Surgically Induced TRP}

A standardized rumenotomy was performed via a left flank laparotomy in standing, nonsedated cows. Local anesthesia was achieved with a proximal paravertebral block using 60 to $80 \mathrm{~mL}$ of lidocaine (Veto- 
quinol Canada Inc.). After rumen incision, the gastric compartments were explored for the presence of foreign bodies. A 10-cm-diameter stainless steel circular claw was inserted into the muscularis tissue of the anteriomedial wall of the reticulum, without perforation. Surgery ended after a step-by-step process of cleaning and placing rumenal, peritoneum, muscle, and skin sutures. Postoperative care included daily disinfection of the wound for 6 to $8 \mathrm{~d}$, a light diet for 2 to $3 \mathrm{~d}$, and removal of skin sutures on d 7 . The circular claw remained in place for $21 \mathrm{~d}$. The cows were then euthanized with $40 \mathrm{mg} / \mathrm{kg}$ intravenous sodium pentobarbital (BimedaMTC Animal Health Inc.) and claw implantation was verified by postmortem examination.

\section{Rescue Analgesia}

Rescue analgesia (RA) was initiated based on live assessments completed every day. Cattle received RA when the sum of the values of the VAS (maximum = $100)$, VPS $($ maximum $=25)$, and TPS $($ maximum $=$ $8)$ scores and EDA measurements (maximum $=10)$ surpassed a threshold of 71.5 (i.e., $>50 \%$ of the total). Drugs for RA consisted of tolfenamic acid $(2 \mathrm{mg} / \mathrm{kg}$ per 48 h, i.m.), butorphanol (0.1 mg/kg, s.c.), or both. The mean duration of postoperative analgesia was defined as the mean time from $\mathrm{h} 0$ to the time at which $\mathrm{RA}$ was first required. The cumulative number of RA doses was recorded at each time point and used for further analyses.

\section{CSF Biomarkers}

Approximately $5 \mathrm{~mL}$ of CSF was sampled following lumbar puncture performed with an 18-gauge $\times$ $70-\mathrm{mm}$ needle attached to a $10-\mathrm{mL}$ syringe. Any CSF sampling with trace blood was discarded and not analyzed further. The CSF collected was transferred into 3 prechilled tubes (Vacutainer, Becton Dickinson Co., Franklin Lakes, NJ) and stored at $-80^{\circ} \mathrm{C}$ until assayed.

CSF Proteomic Determination. Protein detection was performed using SDS-PAGE as previously described (Laemmli, 1970) with $25 \mu \mathrm{L}$ of CSF. The gel was then stained and destained with Coomassie Brilliant Blue R-250 solution (no.161-0436 and no.161-0438 for staining and destaining steps, respectively; Bio-Rad Laboratories, Hercules, CA). A single lane of gel around the mass of interest was cut into identical small pieces and in-gel tryptic digestion was performed according to the method of the trypsin profile in-gel digestion (IGD) kit (no. PP010; Sigma-Aldrich, Oakville, ON, Canada).

Protein identification was performed by HPLC-MS. The observed ions $(m / z)$ were surveyed using the MASCOT search engine (http://www.matrixscience. com/search_form_select.html) and data obtained were validated using mMASS 5.0 (Strohalm et al., 2008). In silico collision-induced dissociation (CID) spectra were generated with mMASS 5.0 and compared with CID spectra generated with a HPLC-tandem MS (MS/ MS) system. The HPLC-MS/MS system comprised a Thermo Surveyor HPLC system and a Thermo Advantage quadrupole ion trap mass spectrometer (Thermo Scientific, San Jose, CA). Data were acquired and analyzed with Xcalibur 1.4 (Thermo Scientific). Identification was based on a previous published method (Steen and Mann, 2004).

For protein quantification, $15-\mathrm{kDa}$ proteins on the SDS-PAGE gel were visualized with an imaging system equipped with a cooled charge-coupled device (CCD) camera (Chemi genius2, Syngene; PerkinElmer, Woodbridge, ON, Canada). Semiquantitative analysis was performed by densitometry using GeneTools software by Syngene (PerkinElmer). Protein quantity was evaluated relative to the baseline CSF band density for each bovine sample.

CSF Catecholamine Determination. Briefly, the measurement of CSF noradrenaline by an HPLC system was based on a modification of the method of Remie and Zaagsma (1986) as described by Hjemdahl (1988), the use of which has been reported previously (de Champlain et al., 2007). The detection limit for noradrenaline was $10 \mathrm{pg} / \mathrm{mL}$, and the typical recovery was $98 \%$ for noradrenaline.

\section{MPT}

Mechanical pain thresholds were measured using a mechanical algometer adapted for use in cattle (Chambers et al., 1994) with a 2-mm-diameter probe that has a gradual rate of application to the skin. The cut-off value was set at $22.0 \mathrm{~N}$, as estimated from a preliminary study. The device was attached to the front (or back) of the cow's leg at the mid-metacarpal (tarsal) region. The MPT corresponded to the pressure recorded upon observing a clear behavioral response in the cow (kicking, lifting of the leg, stepping, or a postural change). The measurements were performed in triplicate in both front and rear sites on each leg, resulting in a collection of $\mathrm{n}=24$ values for each cow, at each time point. A 2-min rest period was maintained between 2 successive mechanical stimulations. The sample $(\mathrm{n}=$ 12 cows) median value of all MPT measurements (n $=24$ in each pain-free cow) recorded at $\mathrm{d}-7$ was the reference threshold of mechanical sensitivity. A leg was nonsensitive if its 6 readings were all above or equal to the reference threshold. The decreased number of nonsensitive legs per cow reflected sensitivity to mechanical pressure. 
Table 1. Ethogram of dairy cow behavioral observations (video analysis)

\begin{tabular}{ll}
\hline Behavior & Definition \\
\hline Standing & The cow stands on all its 4 limbs \\
Lying & The cow's body is resting in contact with the floor (on the right or left side) \\
Transition & The cow moves from kneeling to lying down with the body resting in contact with the floor \\
Agitation while lying & While lying down, the cow stretches a leg, steps, kicks, or changes position without going \\
& from lying to standing or from one side to the other \\
Agitation while standing & While standing, the cow stretches a leg, kicks, or changes weight-bearing limb, position, \\
& without going from standing to lying \\
Head, high & The cow's head is at a level just above the shoulder; \\
(Forward or turned) & the cow's neck is either held forward or turned backward \\
Head, low & The cow's head is below the shoulder or touching the floor; \\
(Forward or turned) & the cow's neck is either held forward or turned backward and rests on the body or the floor \\
Teeth & Grinding the teeth \\
Lips & Licking the lips \\
Lick muzzle & Sweeping the tongue over the upper lip and/or nostril \\
Lick wound & Licking the surgical incision site (left flank) \\
Self-grooming & Rubbing the head or any parts of the body against other body parts or stall fixtures, or licking body parts \\
& (except the area of the surgical incision site) \\
Feeding behavior & Pushing the muzzle into feed, chewing feed \\
Rumination & Regurgitation, chewing, and swallowing of previously eaten feed \\
Drinking & The cow's muzzle is positioned in the drinking bowl \\
Idle & The cow is inactive \\
Disturbed by human & A human is present in the cow's stall or a neighboring stall, or the cow is milked or tightly tethered \\
Social interaction & The cow interacts with its neighbor (has its head outside its own stall, or licks or threatens its neighbor) \\
No interest & The cow shows no interest in its neighbor \\
\hline
\end{tabular}

${ }^{1}$ Standing, lying, and transition behaviors are mutually exclusive. For head, high and head, low: head and neck position choices are mutually exclusive. "Disturbed by human" and "no interest" are environmental factors. Each behavior recording takes into account all of body position, head and neck position, and environmental factors.

\section{Spontaneous Behavioral Measurements}

Accelerometry. The accelerometer is an automated device (Actical; Mini Mitter, Bio-Lynx Scientific Equipment, Montreal, QC, Canada) with a bidirectional microchip that quantifies motor activity (MA). Accelerometer recording has been shown to be reliable and valid recording of activity in dairy cows (Müller and Schrader, 2003; 2005) and was responsive to NSAID in calves following dehorning (Theurer et al., 2012). The Actical accelerometer is sensitive to movements in the range of 0.35 to $3.5 \mathrm{~Hz}$. Each device was attached to a halter at the level of the cow's neck and in line with the vertebral axis from $\mathrm{d}-21$ to $\mathrm{d} 21$. The accelerometer was initialized using 15 -s epochs, so that a total number of 5,760 values of MA (unitless) were registered at each time point (from 08:00:00 to 07:59:45 h) for each cow. The average of the 5,760 daily MA recordings was examined for the subsequent analysis.

Automated Video Analysis. Automated video recording was performed using a webcam camera positioned in front of the cows. For every cow, fourteen 5 -min samples were recorded at 0800, 0900, 1200, 1300, 1400, 1500, 2000, 2100, 2200, 0200, 0300, 0400, 0600, and $0700 \mathrm{~h}$ per day of evaluation. An ethogram was constructed based on data from the literature (Krohn and Munksgaard, 1993; Krohn, 1994; Fogsgaard et al., 2012) and our own experience (Table 1). Behavior occurrence was quantified by one blinded observer using analysis software (The Observer version 3.0; Noldus, Tracksys Ltd., Nottingham, UK). Briefly, a count of 1 was assigned each time an event of a coded behavior occurred (frequency) throughout a total time of $70 \mathrm{~min}$ per $24 \mathrm{~h}$. The counts of each behavior were summed and used for further analysis.

\section{Observer-Reported Pain Measures}

One observer assessed the cow's pain using the VAS, a $100-\mathrm{mm}$ horizontal line ranging from 0 (no pain) to 100 (most severe pain), and the VPS, a composite pain scale, which ranged from 0 (no pain) to 25 (severe pain), (Appendix Table A1). A second observer completed the TPS, which comprised 8 dichotomous items (presence $=1$ or absence $=0 ;$ Appendix Table A2); thus, TPS scores ranged from 0 (no pain) to 8 (severe pain).

\section{Physiological and Pathological Measurements}

The determination of EDA (Pain Gauge; Public Health Information Systems Inc., Dublin, OH) has been described previously (Baldridge et al., 2011). Briefly, the 2 electrodes of the device were applied on a cleaned and dried (with isopropyl rubbing alcohol, 70\%) area of skin at the base of the tail. A 2-min delay ensured evaporation of alcohol before EDA measurement. The dermal conductance recorded on the skin was converted into a numerical EDA (no unit) ranging from 0.1 (ab- 
sence of pain or stress) to 9.9 (intense pain). Readings were obtained in triplicate and averaged for analysis.

Jugular blood samples were collected into 5 -mL heparinized tubes, refrigerated for $2 \mathrm{~h}$, and processed within $3 \mathrm{~h}$ of blood collection. Determination of plasma cortisol concentration was carried out using a radioimmunoassay technique (Coat-A-Count; Diagnostic Products Corp., Los Angeles, CA) at the biochemistry and endocrinology laboratory (Diagnostic Service, FMV). Quantification of food consumption and dairy production (milk quantity and quality) and standard clinical evaluations were conducted daily. A certified pathologist (at FMV) performed the autopsy.

\section{Data and Statistical Analyses}

First, the reliability of assessment methods was tested over the baseline period: nonparametric Friedman tests for repeated measures were calculated for each measure recorded at the 3 time points: $\mathrm{d}-21, \mathrm{~d}-15$, and $\mathrm{d}$ -7 . Because none of the methods had any significantly different values, measurements were considered reliable (data not shown). Only d -7 values served as the baseline reference for subsequent analyses.

The mean duration of postoperative analgesia was analyzed with a Kruskal-Wallis test followed by a Wilcoxon-Mann-Whitney test. The Fisher exact test was conducted to evaluate the occurrence rate for required doses of RA. The number of doses of RA by time was presented using the cumulative mean distribution as a descriptive statistic.

The longitudinal data outcomes followed a Poisson distribution (for CSF biomarkers, number of nonsensitive legs, VAS, and plasma cortisol) and were analyzed with generalized estimating equations (GEE) for repeated measures with a logit link function. Cow was included as a repeated effect in the model. Negative binomial regression was applied when data were overdispersed (for video analysis, VPS, TPS, and EDA). A multivariate model was developed with time, group, interaction of group with time, and RA using Wald statistics. To adjust for multiple measurement times in each cow, we used a GEE model with an unstructured or exchangeable correlation matrix. We used the best quasi-likelihood under the independence model criterion for model comparison (Pan, 2001). Model adequacy was verified using a thorough residual analysis (Ziegler et al., 1998). The GEE model yielded estimates of the risk ratio (RR) for each permutation of the interaction term with a $95 \%$ CI of each exponentiated estimate. The $\alpha$-level was adjusted using the Bonferroni correction (original $\alpha$-value divided by the number of comparisons of interest). Thus, significant $P$-values were $0.05 / 21=$ 0.0023 for CSF biomarkers, MPT, and cortisol, 0.05/27
$=0.0018$ for MA and video analysis, and $0.05 / 24=$ 0.002 for VAS, VPS, TPS, and EDA.

As an exploratory psychometric analysis, inter-item correlation coefficients were calculated for VPS and TPS. A correlation coefficient ranging between 0.20 and 0.80 was considered to indicate that items evaluated the same latent variable; that is, pain.

Data are reported as the median with (25-75\%) interquartile range, unless otherwise specified. Two-sided analyses with an $\alpha$-threshold of 0.05 were conducted using SAS software (version 9.2; SAS Institute Inc., Cary, NC).

\section{RESULTS}

\section{Rescue Analgesia}

The mean duration of postoperative analgesia differed between groups [ $\chi^{2}$ (df): $\left.6.09(2), P=0.03\right]$ and was lower in group 1 than in group 2 [6.09 (1), $P=$ 0.01 ; Figure 2A]. We observed no significant difference when group 3 was compared with group 1 [1.59 (1), $P$ $=0.21]$ or group $2[0.40(1), P=0.52]$. The occurrence rate of required doses of RA was not different between groups $(P=0.16)$. The cumulative distribution of administered doses of RA is shown in Figure $2 \mathrm{~B}$ and clearly highlights the difference of evolution between groups 1 and 2. For group 3, the variability was high because of the divergent response obtained in 1 cow compared with the other 2 in the group.

\section{CSF Biomarkers}

CSF Proteomics. By using 1-dimensional SDSPAGE to separate proteins from different CSF collection times according to their size, we observed a difference in the density for a band near $15 \mathrm{kDa}$ (lane 1, Figure 3). This protein was downregulated in CSF samples postsurgery (lane 3 , d 21) compared with CSF from baseline (lane $2, \mathrm{~d}-7$ ) for a cow from group 1 (Figure 3). Five peaks were observed and mass:charge $(\mathrm{m} / \mathrm{z})$ values of tryptic peptides were determined. Protein identification via tryptic peptide mass fingerprinting was performed using the MASCOT search engine, and the protein transthyretin (TTR) from Bos taurus (protein code: gi $\mid 27806789$ ) provided the best fit. The protein contains $147 \mathrm{AA}$ and the sequence coverage was $70 \%$. Moreover, CID spectra for all 5 tryptic peptides $(30-51,56-68,69-90,101-123,124-146)$ were collected and the results were compatible with the tryptic peptide sequences, with y- and b-type fragment ions predominating.

For CSF TTR concentration, the GEE model analysis indicated significant effects for fixed factors (Table 2). 
A

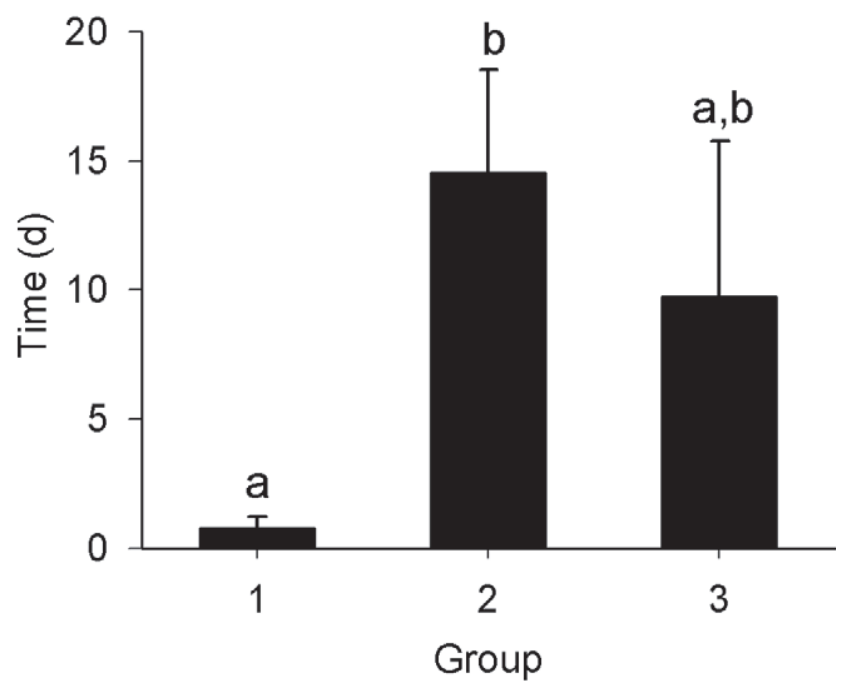

B

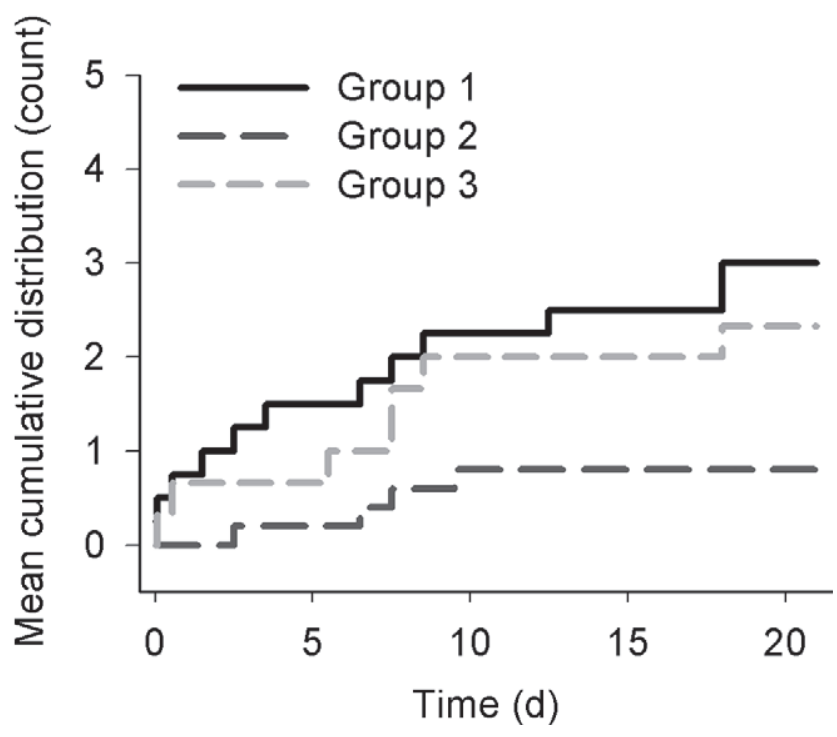

Figure 2. Rescue analgesia is presented with (A) mean time (day) from $\mathrm{d} 0$ to the first required dose of rescue analgesia, and (B) the mean cumulative distribution of number of rescue analgesia doses over time. For the histogram of mean time, different letters ( $a, b)$ indicate significantly different values among treatment groups using the Wilcoxon-Mann-Whitney test. Bonferroni-corrected $\alpha$ level was 0.016. Results are means \pm SEM. Group 1 cows $(n=4)$ were treated with 50 $\mathrm{mg} / \mathrm{kg}$ of intraruminal acetylsalicylic acid at d 0 (h 1); group 2 cows (n $=5$ ) received an i.m. injection of $2 \mathrm{mg} / \mathrm{kg}$ tolfenamic acid $2 \mathrm{~h}$ before surgery on d $0(\mathrm{~h}-2)$, which was repeated at $\mathrm{h} 46$; group 3 cows $(\mathrm{n}=$ 3) received an i.m. injection of $2 \mathrm{mg} / \mathrm{kg}$ tolfenamic acid at $\mathrm{h}-2$ and $\mathrm{h}$ 46 and an epidural injection of morphine sulfate at a dose of $0.1 \mathrm{mg}$ / $\mathrm{kg}$ at $\mathrm{h}-2$, which was repeated at h 22 and $\mathrm{h} \mathrm{46}$, and s.c. butorphanol at a dose of $0.1 \mathrm{mg} / \mathrm{kg}$ at $\mathrm{h}-2$.

In group 1 , relative to $\mathrm{d}-7$, the $\mathrm{RR}$ of decreased CSF TTR was $1.23(95 \% \mathrm{CI}=1.09$ to $1.37 ; P=0.003)$ and $1.58(95 \% \mathrm{CI}=1.36$ to $1.84 ; P<0.001)$ at $\mathrm{d} 15$ and 21 , respectively (Figure 4A). Group 2 cows had 1.14 (95\%
$\mathrm{CI}=1.07$ to $1.20 ; P=0.0003)$ times less TTR at $\mathrm{d} 21$ relative to $\mathrm{d}-7$. Group 3 cows had $1.29(95 \% \mathrm{CI}=1.09$ to $1.52 ; P=0.002)$ times less TTR at d $1-8$ compared with that at $\mathrm{d}-7$, but the other time points did not differ from $\mathrm{d}-7$. For the intergroup comparison, at $\mathrm{d}$ $1-8$, group 1 cows had 1.44 (95\% CI $=1.19$ to $1.75 ; P<$ 0.001) times more TTR than those in group 3 (Figure 4A). Interestingly, at d 21, group 1 had 1.39 (95\% CI $=1.18$ to $1.63 ; P<0.001)$ and $1.82(95 \% \mathrm{CI}=1.50$ to $2.19 ; P<0.001)$ times less TTR than group 2 and group 3, respectively. In addition, group 2 had 1.30 (95\% CI $=1.10$ to $1.53 ; P=0.001)$ times less TTR relative to group 3 at d 21 (Figure $4 \mathrm{~A}$ ). We observed an inverse relationship between the CSF concentration of TTR and the pain hypersensitivity (see below) in this cattle pain model.

CSF Catecholamine. For CSF noradrenaline, the GEE model analysis indicated a significant effect for fixed factors, but an absence of group effect (Table 2 ). In group 1 , relative to $d-7$, the $R R$ of decreased concentration of CSF noradrenaline was 1.24 (95\% CI $=1.09$ to $1.41 ; P=0.0007)$ and $1.17(95 \% \mathrm{CI}=1.07$ to $1.29 ; P=0.0004$ ) at $\mathrm{d} 15$ and 21 , respectively (Figure $4 \mathrm{~B})$. Relative to $\mathrm{d}-7$, CSF noradrenaline did not change with time in groups $2(P=0.61$ at $\mathrm{d} 1-8, P=$ 0.91 at $\mathrm{d} 15$, and $P=0.84$ at $\mathrm{d} 21)$ and $3(P=0.25$ at $\mathrm{d} 1-8, P=0.52$ at $\mathrm{d} 15$, and $P=0.36$ at $\mathrm{d} 21)$. We observed no significant difference between groups for CSF noradrenaline at any time point.

\section{MPT Sensitivity}

The reference threshold for sensitivity to MPT was $11.9 \mathrm{~N}$ at $\mathrm{d}-7$. The number of nonsensitive $\operatorname{leg}(\mathrm{s})$ was equally distributed in each group at baseline $(\mathrm{d}-7)$. For the number of nonsensitive legs, fixed effects were significant in the GEE model analysis (Table 2). Group 1 was $3.39(95 \% \mathrm{CI}=1.91$ to $6.02 ; P<0.001)$ and $3.11(95 \% \mathrm{CI}=1.89$ to $5.18 ; P<0.001)$ times more likely to develop hypersensitivity (a decrease in the number of nonsensitive legs) at d 15 and 21 relative to $\mathrm{d}-7$, respectively (Figure $4 \mathrm{C}$ ). We found no significant change with time for groups 2 and 3 . At both d 15 and 21, group 1 cows were hypersensitive compared with group $2(\mathrm{RR}=5.71,95 \% \mathrm{CI}=2.54$ to $8.29 ; P<0.001$, and $\mathrm{RR}=4.67,95 \% \mathrm{CI}=3.33$ to $6.57 ; P<0.001$, respectively) and group $3(\mathrm{RR}=5.18,95 \% \mathrm{CI}=3.62$ to $7.26 ; P<0.001$, and $\mathrm{RR}=4.75,95 \% \mathrm{CI}=3.68$ to $6.11 ; P<0.001$, respectively; Figure 4C).

\section{Spontaneous Behavioral Measurements}

Accelerometry. For daily MA, the GEE model analysis indicated main effects for fixed factors (Table 


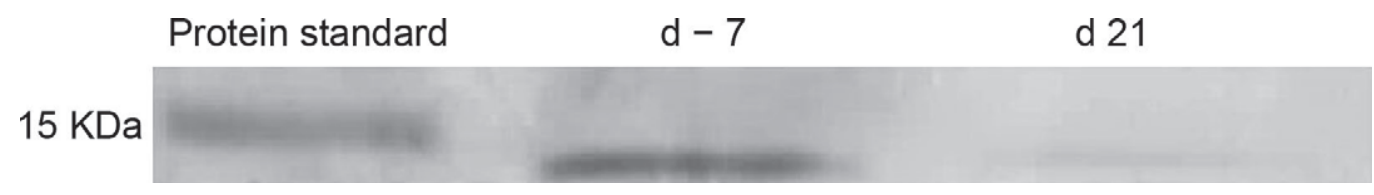

Figure 3. Relative protein quantification with one-dimensional gel showing the difference in band density between $25 \mu \mathrm{L}$ of baseline cerebrospinal fluid (CSF) (lane 2, d -7 ) and $25 \mu \mathrm{L}$ of postsurgery CSF sample (lane $3, \mathrm{~d} 21$ ) for a protein approximately $15 \mathrm{kDa}$ (lane $1=$ molecular weight standard).

2). At d -7 , group 3 cows were 1.57 (95\% CI $=1.18$ to $2.08 ; P=0.0018)$ times more active than cows in group 1. For both groups 2 and 3 , MA was lower at $\mathrm{d} 0(P=$ 0.0005 and $P<0.001$ ), d 1 (both $P<0.001$ ), d 2 (both $P<0.001$ ), d 5 (both $P<0.001$ ), and d 19 (both $P<$ 0.001 ) compared with $\mathrm{d}-7$. At d 2 , group 3 cows were $1.97(95 \% \mathrm{CI}=1.35$ to $2.86 ; P<0.001)$ times more likely to increase MA than group 2 cows (Figure 5A).

Automated Video Analysis. The GEE model allowed planned comparison analysis of the following spontaneous behaviors: "agitation while lying," "feeding behavior," "head low/forward," and "head high/turned" (Tables 1 and 2).

In both groups 2 and 3, the occurrence rate of "agitation while lying" was lower at $\mathrm{d} 2$ relative to $\mathrm{d}-7$ ( $P$ $=0.0003$ and $P<0.001$, respectively; Figure 5B). The occurrence rate of "agitation while lying" was also lower at $\mathrm{d} 5$ relative to $\mathrm{d}-7$ in group $3(P<0.001)$. Group 1 cows had $3.35(95 \% \mathrm{CI}=2.05$ to $5.47 ; P<0.001)$, $2.79(95 \% \mathrm{CI}=1.44$ to $5.13 ; P=0.002)$, and $2.13(95 \%$ $\mathrm{CI}=1.48$ to $3.07 ; P<0.001)$ times more events of "agitation while lying" than those in group 3 at d 2, 5, and 19, respectively (Figure 5B). Group 2 also had 2.19 $(95 \% \mathrm{CI}=1.80$ to $2.67 ; P<0.001)$ and $3.40(95 \% \mathrm{CI}=$ 1.73 to $6.65 ; P<0.001)$ times more events of "agitation while lying" than group 3 at d 2 and 5 , respectively.

The occurrence rate of "feeding behavior" significantly increased at $\mathrm{d} 2$ relative to $\mathrm{d}-7$ in group $3(P=$ 0.0006 ; Figure $5 \mathrm{C})$. At $\mathrm{d} 2$, the RR of "feeding behavior" in group 2 was $5.62(95 \% \mathrm{CI}=2.52$ to $12.59 ; P<$ $0.001)$ and in group $3,4.16(95 \% \mathrm{CI}=2.64$ to $6.57 ; P$ $<0.001$ ) times higher relative to group 1 (Figure $5 \mathrm{C}$ ).

In group 1, the occurrence rate of "head low/forward" decreased at both d 0 and d 2 relative to $\mathrm{d}-7$ (both $P$ $<0.001$; Figure 5D). Group 2 did not change over time. In group 3, the occurrence rate of "head low/forward" decreased at $\mathrm{d} 0$ relative to $\mathrm{d}-7(P<0.001)$, whereas the occurrence rate of "head low/forward" increased at $\mathrm{d} 1(P<0.001)$, d $2(P=0.001)$, d $5(P=0.0013)$, and d $19(P<0.001)$ relative to $\mathrm{d}-7$. At d 2 , group 1 had $2.74(95 \% \mathrm{CI}=1.64$ to $4.58 ; P<0.001)$ and $2.66(95 \%$ $\mathrm{CI}=1.89$ to $3.74 ; P<0.001)$ times fewer events of

Table 2. Mixed linear regression models ( $P$-value) for each of the pain outcomes for 12 Holstein cows and results of the planned comparison at baseline

\begin{tabular}{lccccc}
\hline & \multicolumn{3}{c}{ P-value } & $\begin{array}{c}\text { Group difference } \\
\text { at baseline, } \\
\text { relative risk } \\
\text { Pain outcome }\end{array}$ \\
\cline { 2 - 5 } & Time $(\mathrm{T})$ & Group $(\mathrm{G})$ & $\mathrm{T} \times \mathrm{G}$ & $\begin{array}{c}\text { Rescue } \\
\text { analgesia }\end{array}$ & \\
\hline CSF TTR & $<0.0001$ & $<0.0001$ & $<0.0001$ & $<0.0001$ & \\
CSF NOR & 0.004 & 0.42 & $<0.0001$ & $<0.0001$ & \\
MPT & $<0.0001$ & $<0.0001$ & $<0.0001$ & $<0.0001$ & \\
Accelerometry & $<0.0001$ & 0.007 & $<0.0001$ & $<0.0001$ & Group 1 $<$ Group 3 \\
Agitation while lying & $<0.0001$ & 0.0002 & $<0.0001$ & 0.17 & \\
Feeding behavior & 0.0002 & 0.007 & $<0.0001$ & $<0.0001$ & \\
Head low/forward & $<0.0001$ & 0.50 & $<0.0001$ & $<0.0001$ & \\
Head high/turned & $<0.0001$ & 0.25 & $<0.0001$ & $<0.0001$ & \\
VAS & 0.25 & 0.29 & $<0.0001$ & $<0.0001$ & \\
VPS & $<0.0001$ & 0.21 & $<0.0001$ & $<0.0001$ & \\
TPS & $<0.0001$ & 0.57 & $<0.0001$ & $<0.0001$ & \\
EDA & $<0.0001$ & 0.004 & $<0.0001$ & $<0.0001$ & \\
Plasma cortisol & $<0.0001$ & 0.53 & $<0.0001$ & $<0.0001$ & \\
\hline
\end{tabular}

${ }^{1} \mathrm{CSF}$ TTR $=$ cerebrospinal fluid transthyretin; CSF NOR $=$ cerebrospinal fluid noradrenaline; MPT $=$ mechanical pain threshold; VAS = visual analog scale; VPS = veterinarian pain scale; TPS = technician pain scale; $\mathrm{EDA}=$ electrodermal activity.

${ }^{2}$ Group 1 cows $(\mathrm{n}=4)$ were treated with $50 \mathrm{mg} / \mathrm{kg}$ of intraruminal acetylsalicylic acid at $\mathrm{d} 0$ (h 1 ); group 3 cows $(\mathrm{n}=3)$ received an i.m. injection of $2 \mathrm{mg} / \mathrm{kg}$ tolfenamic acid at $\mathrm{h}-2$ and $\mathrm{h} 46$ and an epidural injection of morphine sulfate at a dose of $0.1 \mathrm{mg} / \mathrm{kg}$ at $\mathrm{h}-2$, which was repeated at $\mathrm{h} 22$ and $\mathrm{h} 46$, and s.c. butorphanol at a dose of $0.1 \mathrm{mg} / \mathrm{kg}$ at $\mathrm{h}-2$. 

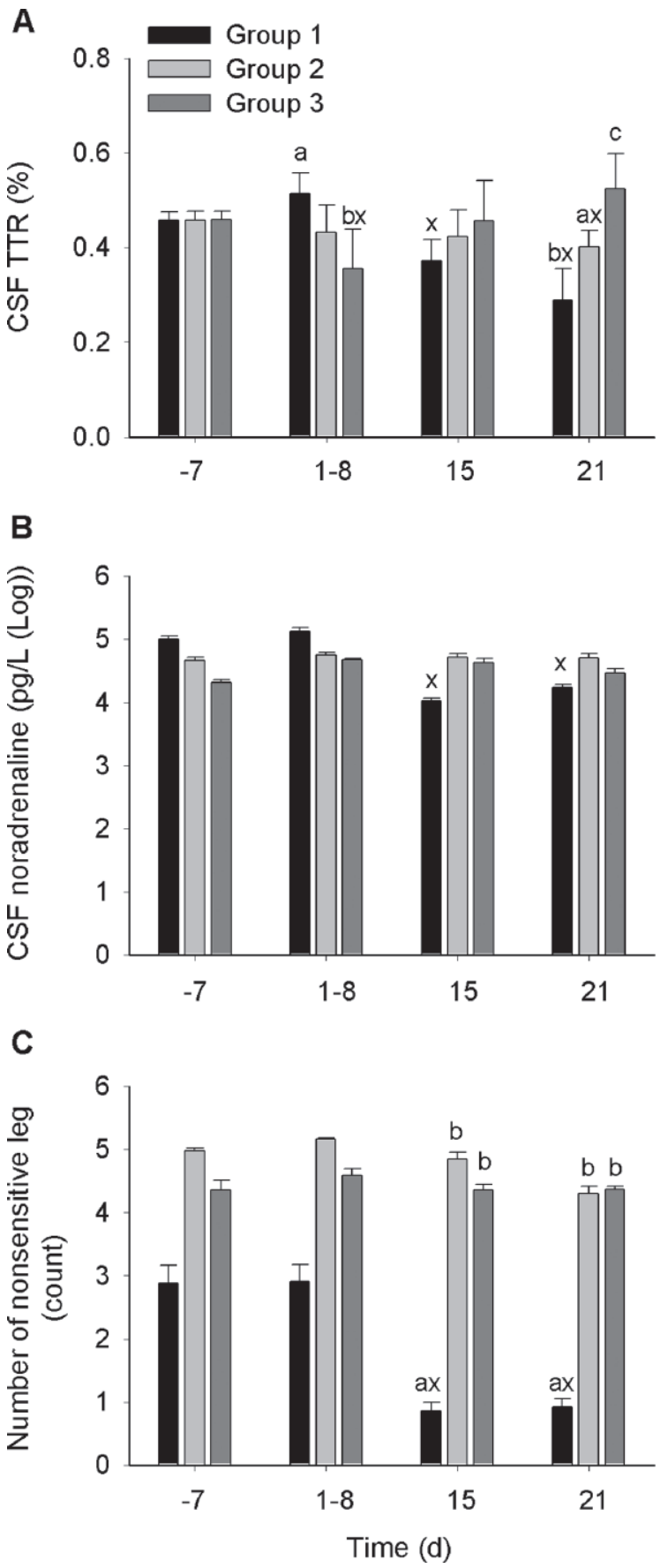

Figure 4. (A) Cerebrospinal fluid (CSF) transthyretin (TTR), (B) CSF noradrenaline, and (C) number of nonsensitive legs by group over time (day). Data are presented as LSM estimates and SE for groups of $\mathrm{n}=3$ to 5 cows. Letter $\mathrm{x}$ denotes a significant difference compared with $\mathrm{d}-7$; letters a-c indicate significantly different values among treatment groups. Bonferroni-corrected $\alpha$ level was 0.0023. Results are LSM \pm SE. Group 1 cows $(\mathrm{n}=4)$ were treated with $50 \mathrm{mg} / \mathrm{kg}$ of intraruminal acetylsalicylic acid at d 0 (h 1$)$; group 2 cows $(\mathrm{n}=5)$ received an i.m. injection of $2 \mathrm{mg} / \mathrm{kg}$ tolfenamic acid $2 \mathrm{~h}$ before surgery on d $0(\mathrm{~h}-2)$, which was repeated at $\mathrm{h} 46$; group 3 cows $(\mathrm{n}=3)$ received an i.m. injection of $2 \mathrm{mg} / \mathrm{kg}$ tolfenamic acid at $\mathrm{h}-2$ and $\mathrm{h} 46$ and an epidural injection of morphine sulfate at a dose of $0.1 \mathrm{mg} / \mathrm{kg}$ at $\mathrm{h}-2$, which was repeated at h 22 and h 46 , and s.c. butorphanol at a dose of $0.1 \mathrm{mg} / \mathrm{kg}$ at $\mathrm{h}-2$. "head low/forward" than groups 2 and 3, respectively (Figure 5D). At d 5, the RR in group 3 was $2.74(95 \%$ $\mathrm{CI}=1.64$ to $4.58 ; P<0.001)$ times higher relative to that in group 2 (Figure 5D).

In group 1, the occurrence rate of "head high/turned" significantly decreased at d 0 compared with $\mathrm{d}-7(P=$ 0.0002 ) and decreased in group 3 at $\mathrm{d} 2$ compared with $\mathrm{d}-7(P<0.001 ;$ Figure 5E). At $\mathrm{d} 2$, the RR in group 2 of "head high/turned" was 3.03 (95\% CI $=2.26$ to 4.06; $P<0.001$ ) times more relative to group 3 (Figure 5E).

\section{Observer-Reported Pain Measures}

Results of the GEE models are shown in Table 2. For VAS, at $\mathrm{d} 2$, the RR of increased VAS score in group 1 was 2.15 (95\% CI $=1.34$ to $3.45 ; P=0.0015)$ times more relative to group 2 (Figure 6 ). We observed no significant difference between groups for the other time comparison for VAS, VPS, and TPS (data not shown).

Cronbach's coefficient $\alpha$, calculated as an exploratory analysis, was 0.67 for the VPS. The poor correlation between the VPS total score and the following physiological items: VPS-T $(r=0.19)$, VPS-HR $(r=$ $0.10)$, and VPS-RR $(r=0.12)$ indicated that these items were not concordant with the VPS score (see Appendix 1 for definitions). The remaining items: VPS-BP $(\mathrm{r}=0.27)$, VPS-A $(\mathrm{r}=0.54)$, VPS-WP $(\mathrm{r}$ $=0.30)$, VPS-App $(\mathrm{r}=0.60)$, VPS-Face $(\mathrm{r}=0.59)$, and VPS-Post $(\mathrm{r}=0.55)$ had acceptable correlations with the VPS score, showing that these items were homogeneous. For the TPS, Cronbach's coefficient $\alpha$ was 0.71 and correlations of each item with the total score showed that the items were concordant with the total score $(0.21<\mathrm{r}<0.70)$.

\section{Physiological and Pathological Measurements}

The GEE models for EDA and plasma cortisol indicated significant effects for time, the interaction of group with time, and RA (all $P<0.001$; Table 2).

At d -7 , EDA (unitless) did not differ between groups 1 [median (25-75\% interquartile range, IQR) $=2.2$ $(2.1-2.7)], 2[2.4(2.2-2.8)]$, and 3 [1.9 (1.8-1.9)]. The EDA measurements increased, on average, by $12.4 \%$ for about $48 \mathrm{~h}$ in all groups and no difference was detected between groups during this time (data not shown). At d 15 only, the RR of decreased EDA in group 3 [EDA, $1.6(1.4-1.9)]$ was $2.37(95 \% \mathrm{CI}=1.36$ to $4.12 ; P=$ $0.002)$ and $2.40(95 \% \mathrm{CI}=1.53$ to $3.77 ; P<0.001)$ relative to group 1 [EDA, $2.3(1.5-4.0)]$ and group 2 [EDA, $4.0(2.1-4.2)]$.

At d -7 , plasma cortisol concentrations (median and IQR) were not different between groups 1 [22.45 (14.70-31.95) nmol/L), 2 [21.90 (14.70-31.95) nmol/L], 
A
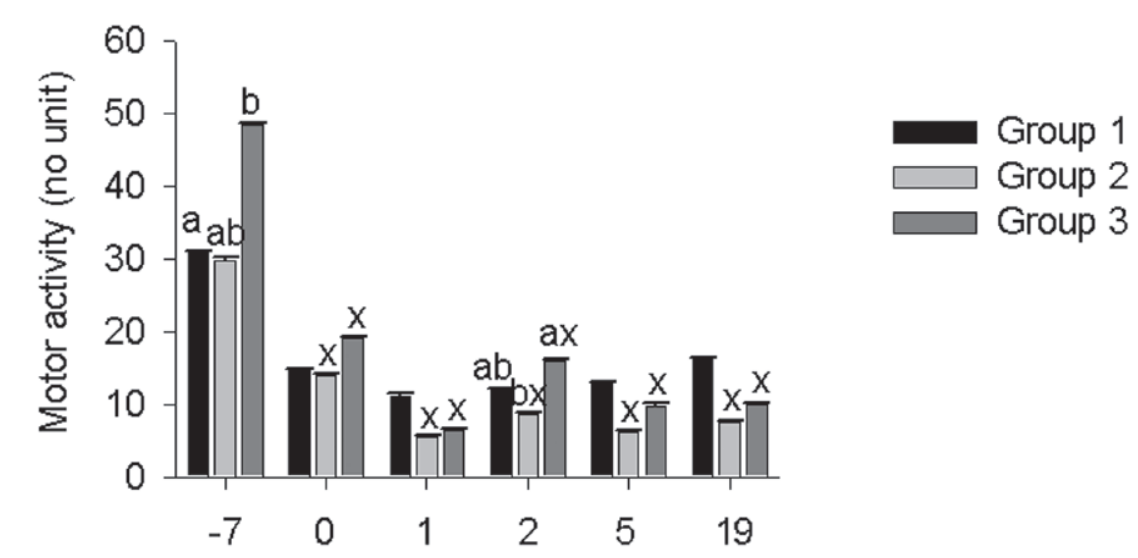

B
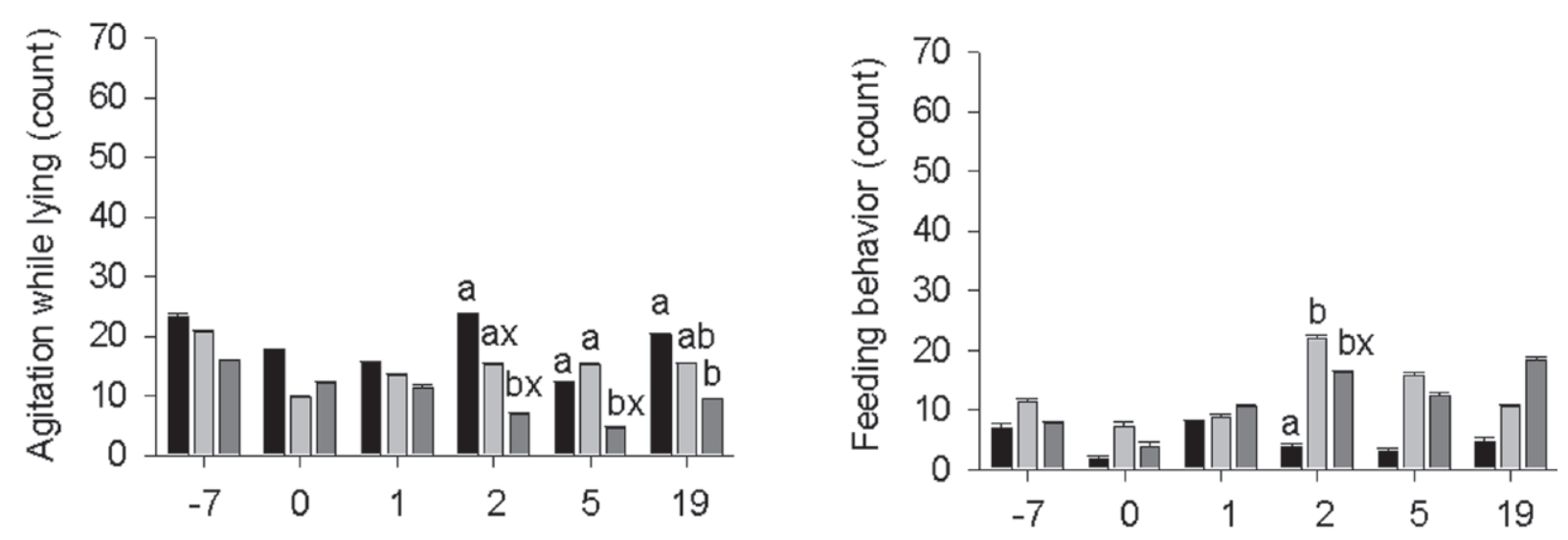

D

E
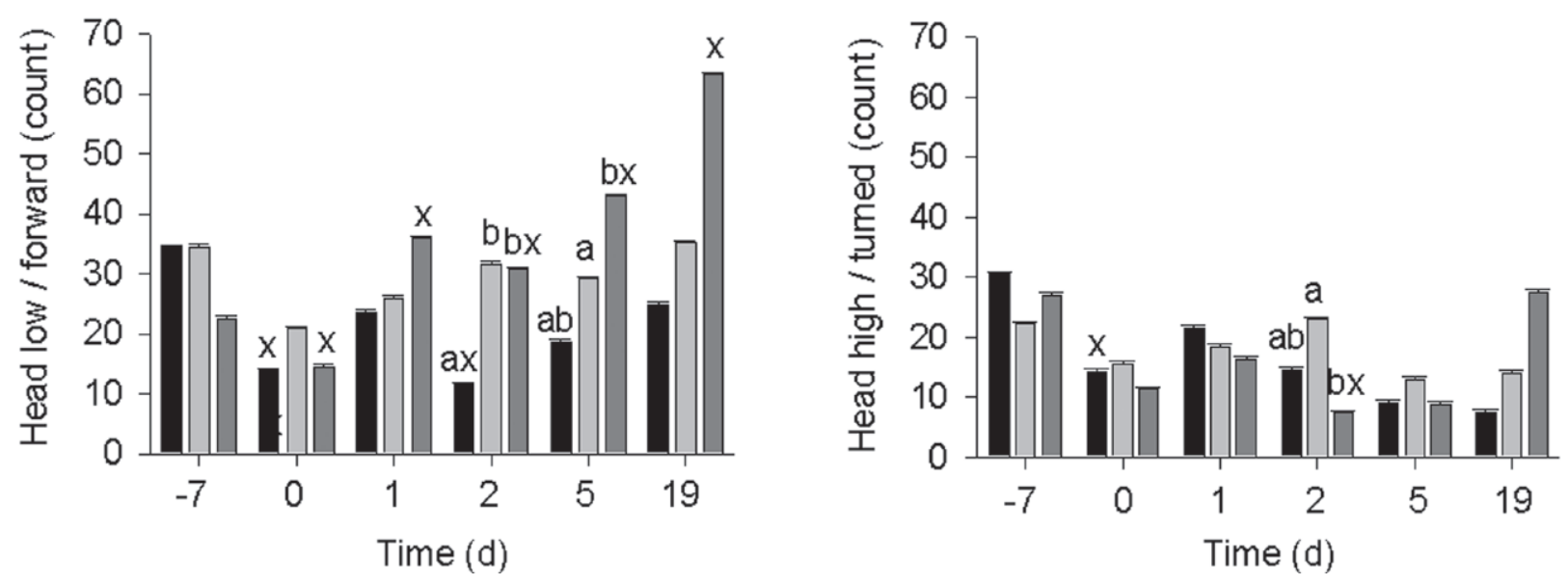

Figure 5. (A) Motor activity and the spontaneous behaviors (B) lying with agitation, (C) feeding behavior, (D) head low/forward, and (E) head high/turned by group over time. Data are presented as LSM estimates and SE for groups of $\mathrm{n}=3$ to 5 cows. Letter $\mathrm{x}$ denotes a significant difference compared with $\mathrm{d}-7$; letters $\mathrm{a}$ and $\mathrm{b}$ indicate significantly different values among treatment groups. Bonferroni-corrected $\alpha$ level was 0.0018. Results are LSM \pm SE. Group 1 cows $(\mathrm{n}=4)$ were treated with $50 \mathrm{mg} / \mathrm{kg}$ of intraruminal acetylsalicylic acid at d 0 (h 1); group 2 cows $(\mathrm{n}=5)$ received an i.m. injection of $2 \mathrm{mg} / \mathrm{kg}$ tolfenamic acid $2 \mathrm{~h}$ before surgery on $\mathrm{d} 0(\mathrm{~h}-2)$, which was repeated at $\mathrm{h} 46$; group 3 cows $(\mathrm{n}=$ 3) received an i.m. injection of $2 \mathrm{mg} / \mathrm{kg}$ tolfenamic acid at $\mathrm{h}-2$ and $\mathrm{h} 46$ and an epidural injection of morphine sulfate at a dose of $0.1 \mathrm{mg} / \mathrm{kg}$ at $\mathrm{h}-2$, which was repeated at $\mathrm{h} 22$ and $\mathrm{h} 46$, and s.c. butorphanol at a dose of $0.1 \mathrm{mg} / \mathrm{kg}$ at $\mathrm{h}-2$. 


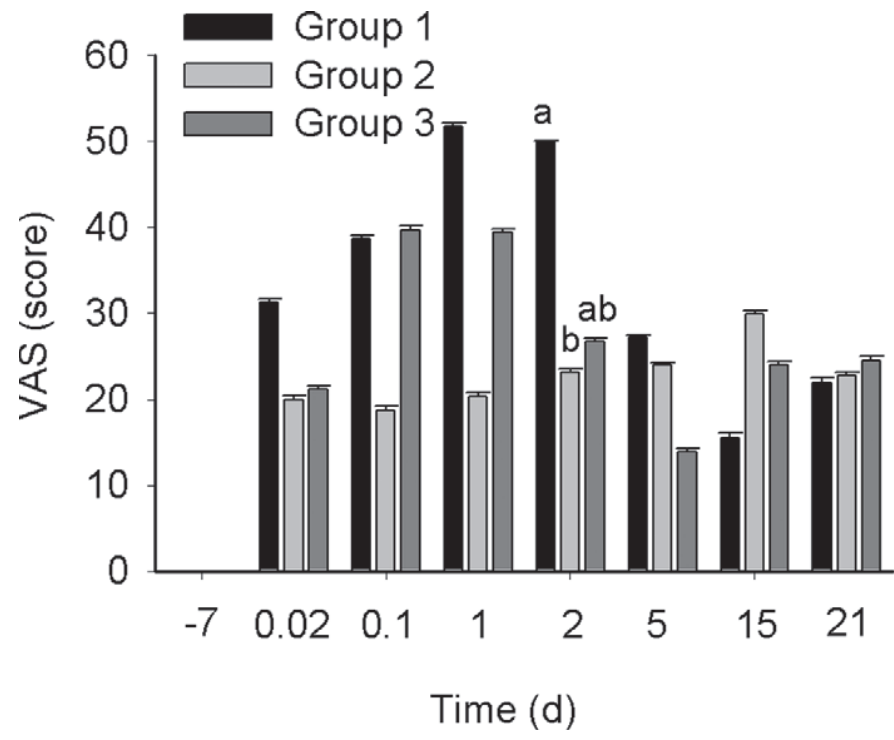

Figure 6. Visual analog scale (VAS) by group over time. Data are presented as LSM estimates and SE for groups of $\mathrm{n}=3$ to 5 cows. Time points 0.02 and 0.10 correspond to $\mathrm{d} 0$ at $2 \mathrm{~h}$ and $10 \mathrm{~h}$, respectively. At each time point, different letters $(\mathrm{a}, \mathrm{b})$ indicate significantly different values among treatment groups. Bonferroni-corrected $\alpha$ level was 0.002 . Results are $\mathrm{LSM} \pm \mathrm{SE}$. Group 1 cows $(\mathrm{n}=4)$ were treated with $50 \mathrm{mg} / \mathrm{kg}$ of intraruminal acetylsalicylic acid at d 0 (h 1); group 2 cows $(\mathrm{n}=5)$ received an i.m. injection of $2 \mathrm{mg} / \mathrm{kg}$ tolfenamic acid 2 $\mathrm{h}$ before surgery on $\mathrm{d} 0(\mathrm{~h}-2)$, which was repeated at $\mathrm{h} 46$; group 3 cows $(\mathrm{n}=3)$ received an i.m. injection of $2 \mathrm{mg} / \mathrm{kg}$ tolfenamic acid at $\mathrm{h}-2$ and $\mathrm{h} 46$ and an epidural injection of morphine sulfate at a dose of $0.1 \mathrm{mg} / \mathrm{kg}$ at $\mathrm{h}-2$, which was repeated at h 22 and h 46 , and s.c. butorphanol at a dose of $0.1 \mathrm{mg} / \mathrm{kg}$ at $\mathrm{h}-2$.

and 3 [21.80 (16.60-27.20) nmol/L]. The concentration of plasma cortisol increased, on average, by $241 \%$ for about $48 \mathrm{~h}$ in all groups and no difference between groups was observed during this time (data not shown). At d 7, group 1 [31.6 (20.7-52.4) nmol/L] had 1.39 $(95 \% \mathrm{CI}=1.22$ to $1.57 ; P<0.001)$ times higher plasma cortisol compared with group 3 [14.6 (10.0-23.8) $\mathrm{nmol} / \mathrm{L}]$. In addition, group $2[27.7(19.3-36.4) \mathrm{nmol} / \mathrm{L}]$ had $1.42(95 \% \mathrm{CI}=1.24$ to $1.62 ; P<0.001)$ times higher plasma cortisol compared with group 3 at the same time. At d 21, the RR of increased cortisol in group $1[40.0(25.6-55.9) \mathrm{nmol} / \mathrm{L}]$ was $1.49(95 \%$ CI $=1.23$ to $1.82 ; P<0.001)$ relative to group $2[22.4$ $(18.5-22.8) \mathrm{nmol} / \mathrm{L})$. The RR of increased cortisol was $1.34(95 \% \mathrm{CI}=1.12$ to $1.59 ; P=0.0008)$ in group 3 [30.4 (15.5-54) nmol/L) relative to group 2. Other significant differences between groups did not emerge (data not shown).

Daily observation of cattle showed a huge decrease in feed intake (as mentioned in the video analysis section with a between-groups difference) and decreased qualitative (both protein and fat) and quantitative milk production; significant signaling of inflammation (hematological analyses including circulating leucocyte and neutrophil counts, fibrinogen, and total plasma protein) was also observed (data not shown), with few statistically significant differences between groups. Autopsy confirmed local inflammation with fibrin, reticular abscesses, and lack of reticulum perforation in all cows, to the same extent (reticular abscesses, extended inflammation, fibrin, necrosis around the foreign body and skin incision, moderate signs of peritonitis). The extent of tissue lesions was similar among cows and it was impossible to know whether lesions induced the same level of pain severity.

\section{DISCUSSION}

Outcome measures used in this study were used to detect negative outcomes (difference between baseline and post TRP induction; i.e., specificity to pain detection) and to predict the responsiveness to known analgesics (difference between the expected 3 levels of pain severity provided by the 3 levels of analgesia; i.e., sensitivity to analgesia). Our hypothesis was that the analgesic protocol used in group 1 (single postoperative aspirin administration) would be poor, close to a negative control, whereas the highest level of analgesia would be present in group 3, and intermediate in group 2. None of the tested methods except one (CSF TTR) consistently demonstrated predicted pain levels (pain higher in group 1 than in group 2, which was higher than in group 3). First, the highest predicted level of pain intensity (group 1) at d 21 had lower CSF TTR, decreased CSF noradrenaline, and increased mechanical hypersensitivity. Of the 3 methods cited above, CSF TTR downregulation demonstrated the best ability to predict the responsiveness to analgesics. Second, behavioral analysis in group 1 demonstrated a higher level of discomfort compared with group 3, as reflected by a trend for increased MA (d 5 and d 19), more events of "agitation while lying" (at d 2, 5, and 19), and fewer events of "feeding behavior." In contrast, the high occurrence of "head low/forward" and decreased MA lasted throughout the period from d 1 to $\mathrm{d} 21$ in group 3 , suggesting that group 3 cows were less alert. Third, subjective evaluations made up of the VAS, VPS, and TPS scores, and physiological measurements (EDA and plasma cortisol measurements) did not consistently reflect expected levels of pain intensity, but for a limited number of time points of assessment denoted higher intensity of pain in group 1 with VAS, EDA, and cortisol. These findings support the need for measurement of central pain mechanisms and corresponding behavioral evaluation in the assessment of bovine pain in clinical trials. The present study also underlines the potential application of a potent pain biomarker, TTR, in assessing chronic pain. 
Rescue analgesia was given to keep cows out of significant pain and distress. Use of RA could obscure the interpretation of the data, but in fact, the effects of pain itself could also produce unwanted variability (Carbone, 2011). In this study, RA did not obstruct data interpretation because we included information about RA in our statistical model to explain part of the variability of outcome data. In addition, information about RA was used as a surrogate to assess pain. First, the short time for the first required RA dose suggested that group 1 cows had more postoperative pain than cows of groups 2 and 3, whereas the latter were similar. Second, in contrast to our hypothesis, the occurrence rate of administration of RA in group 3 was intermediate between that of group 1 and group 2. It is possible that the sedative effect of the opioids used in group 3 was a confounding factor for assessing pain or that the small sample size in group 3 led to a type I error. It also should be noted that the decision to administer RA was based on live evaluation via observer-reported pain assessment (VAS, VPS, and TPS) as well as EDA. All of these measures have shown poor psychometric qualities in the current study, so the validity of the decision to administer RA is, a posteriori, doubtful. Moreover, the threshold (50\% of the total) for determining whether RA was to be administered was arbitrary because we were unaware of equivalent data in the literature.

This experimental chronic pain study showed a longlasting decrease in CSF TTR and noradrenaline release, as well as the presence of mechanical hypersensitivity in group 1. This indicates activation of centralized pain mechanisms. In addition, the change in MPT and CSF TTR, as observed in group 1, was suppressed (almost totally) by preemptive multimodal analgesia in group 3. Taken together, these findings suggest that the activity of the descending inhibitory pain control and a concomitant increase of TTR in the dorsal horn of the spinal cord in the visceral pain state might be related to the antihyperalgesic effects of preemptive multimodal analgesia.

In this report, proteomic analysis allowed identification of TTR. This $55-\mathrm{kDa}$ protein is composed of 4 identical subunits of approximately $14 \mathrm{kDa}$ each, synthesized predominantly in cells of the choroid plexus and liver and secreted into the CSF or plasma, respectively (Schreiber, 2002). The role of TTR is recognized mainly in the transport of thyroxin (Monaco, 2000; Power et al., 2000), in neuroprotection (Santos et al., 2010), and in degenerative and chronic diseases in human adults (Richardson, 2007). Interestingly, TTR has been reported in pain studies to be decreased in rat spinal cord after injury (Afjehi-Sadat et al., 2010) and in blood following herniotomy surgery in human patients (Fricova et al., 2010). Previously, TTR was identified in human serum as an inhibitor of constitutive IL-1 $\beta$ production by human endothelial cells, and it also inhibited LPS-induced IL-1 $\beta$ production by various cell types (Borish et al., 1992). Interleukin-1 $\beta$ is known to play a central role in many inflammatory processes. In addition, IL-1 $\beta$ is implicated in spinal cord central sensitization (Milligan and Watkins, 2009). Probably, TTR functions by inhibiting the processing of newly synthesized peptides for secretion and thus may act as an endogenous antiinflammatory mediator. It has also been demonstrated that TTR knockout mice, compared with wild-type mice, show a 2 -fold increase in CSF neuropeptide $\mathrm{Y}$ and even more in the brain (hippocampus) and the dorsal root ganglion of the sciatic nerve (associated with a 1.5-fold increase in substance P; Nunes et al., 2006). Both excitatory neuropeptides are involved in pain transmission and modulation. In the current study, TTR was able to differentiate between groups at d 21, supporting the original hypothesis. In addition, we showed that at d 1-8, TTR decreased in group 3, but increased in group 1, and, at d 21, TTR decreased in group 1. This finding supports that neuronal plasticity exists in the process of CSF TTR release caused by the pain model, where we could hypothesize that TTR counteracts the increased release of inflammatory cytokines and excitatory neurotransmitters. With time, we could propose hypothetically their sustained release to be associated with a high degree of TTR "consumption" as buffer, leading to decreased TTR expression in chronic pain.

This study also demonstrated that RA ameliorated CSF TTR levels. In line with this, a previous study showed a decrease in plasma TTR after inflammation but an increase in plasma TTR after administration of glucocorticoids or NSAID (Richter et al., 1983; Ingenbleek and Young, 2002). Thus, TTR release may reflect endogenous inhibitory control of pain in response to inflammatory and neuropathic stimulation. In addition, this TRP model decreased feeding behavior, and others have demonstrated that TTR is influenced by malnutrition and stress (Ingenbleek and Young, 2002). Therefore, TTR might be an indicator of both lack of welfare and pain in dairy cattle.

The concentration of CSF noradrenaline was constant throughout the 21-d period in groups 2 and 3, whereas CSF noradrenaline was decreased in group 1 at d 15 and 21. The latter could indicate sustained activation of the descending noradrenergic inhibitory pain pathway up to d $1-8$, followed by fatigue of the same pathway. This was in line with previous studies that reported decreased CSF noradrenaline release following traumatic pain in patients (Cui et al., 2012). Nevertheless, CSF noradrenaline was a moderately effective pain biomarker because it did not differentiate 
between the 3 expected levels of analgesia. In addition, group 1 demonstrated large, undesirable variability in this measure. In fact, both the lack of sensitivity and the variability of CSF noradrenaline measurement may be due to the effects of various confounding factors. For example, stress (Saito et al., 2002) and comorbidity between pain and stress (Tsigos and Chrousos, 2002) increase CSF noradrenaline. In the present study, we also observed stress on the basis of high plasma cortisol and EDA, suggesting that stress might affect CSF noradrenaline release. It is also possible that RA might have increased CSF noradrenaline concentrations in this study, because CSF noradrenaline release has been observed following administration of gabapentin (Hayashida et al., 2008) and NSAID (Fiebich et al., 2006). It appears that CSF noradrenaline is responsive in some part to chronic pain, but it suffers from the aforementioned limitations that would likely restrict its usefulness in testing analgesic drug efficacy in cattle.

Allodynia associated with mechanical sensitivity due to underlying centralized pain was assessed with MPT. Both a stress response (Herskin et al., 2004) and decreased reactivity associated with stoic behavior (Rasmussen et al., 2011) were previously reported in dairy cows with mastitis and might confound the sensitization-pain relationship. For this reason, mechanical pain tests were repeated at multiple sites on each leg, and in the absence of a human experimenter, controlling for effects of variations in sensitivity of different sites on a single limb and for handling stress. A delayed and longlasting mechanical hypersensitivity was shown in group 1 , which confirmed central sensitization in cattle and validated some sensitivity of this method. We found no obvious difference in mechanical sensitivity between groups 2 and 3, suggesting that the responsiveness of this test to different pain intensities could be limited. Interestingly, a clear protective and long-lasting antihyperalgesic effect of preemptive tolfenamic acid was observed in group 2 cows at d 21, whereas in group 1 cows, RA consisting mainly of tolfenamic acid did not produce hyposensitivity at that time point. This latter finding is in accordance with previous studies in which ketoprofen use had no effect on mechanical sensitization in clinically lame cows (Whay et al., 1998; Laven et al., 2008). Therefore, the finding of reduced responsiveness to an NSAID when central sensitization is already established supports this assessment method. These current findings emphasize the need for other therapeutic pain management strategies for cattle in pathological pain states, such as centrally acting analgesic drugs (Malreddy et al., 2013).

The pain model affected MA, but group 1 cows were more active than cows in both analgesic groups following pain induction. This is in line with a previous study demonstrating decreased activity in meloxicam-treated cows following dehorning (Heinrich et al., 2010), and higher MA after acute abdominal pain compared with healthy cows (Edwards and Tozer, 2004). The decrease in MA was present in all 3 groups (compared with d $-7)$ and this decrease was responsive (less marked) to preemptive analgesics at d 2 (difference between groups 2 and 3). The interference of subsequent RA made the interpretation of MA data difficult. Importantly, automated video analysis showed early (d 2) dramatic and temporary changes: Group 1 cows had more "agitation while lying," fewer "feeding behavior" events, and fewer "head low/forward" events compared with group 3. These results provide strong evidence of discomfort in group 1 cows, as previously observed in cattle (Edwards and Tozer, 2004; White et al., 2008). Group 1 cows showed more "agitation while lying" from d 2 to 19, which suggested progressive and long-lasting discomfort. Indeed, the best sensitivity and specificity was achieved with the behavior "agitation while lying" for both acute and chronic pain. In contrast, differences were not detected between groups for the spontaneous behavior "lying down." Daily lying time recorded via accelerometer (Newby et al., 2013) did not differentiate ketoprofen-treated cows from a placebo group. Altogether, postural change might not be sensitive to pain. "Feeding behavior" was more frequent in both preemptive analgesic groups relative to group 1 at d 2. Recently, surgical treatment of a displaced abomasum in cows treated with ketoprofen apparently improved their feeding behavior compared with that of placebo-treated cows (Newby et al., 2013). Although feeding behavior is seemingly important in assessing pain, some limitations were shown because of the large individual variability at $\mathrm{d} 2$ and the lack of specificity for pain. Moreover, because feeding behavior has been demonstrated to be altered in myriad conditions affecting cows (Urton et al., 2005; Huzzey et al., 2007; González et al., 2008; Fogsgaard et al., 2012), this behavioral criterion is unlikely to be sensitive and specific for assessing chronic pain. In contrast to a previous study (Mialon et al., 2012), group 1 cows had fewer "head low/forward" behaviors, whereas group 3 cows had more "head low/forward" and fewer "head high/ turned" behaviors. Interpretation of the cow's head position alone is not sufficient because both head and ear position may indicate interest in the environment and may reflect alert behavior. In addition, sedative side effects of the drugs were suggested both by the head positions and the long-lasting decrease in MA, as previously observed in another species (Rialland et al., 2012).

In this study, for the observer-reported pain scores, the best sensitivity was demonstrated with VAS be- 
cause it was the only measure that differentiated between groups at $d 2$. Neither the VPS nor the TPS demonstrated good psychometric (internal consistency and sensitivity) qualities. Thus, validation of the bovine pain scales (VPS and TPS) was not achieved in this study. In particular, for the VPS, scores for the physiological items were poorly correlated with the overall VPS score. Therefore, the physiological items should be discarded in a potential future version of this pain scale.

Plasma cortisol and EDA indirectly measure activation of the hypothalamic-pituitary-adrenal axis and the autonomic nervous system, respectively. Neither method was able to detect different levels of acute pain. These results emphasize that acute pain can be confounded with stress, preventing clear interpretation of cortisol release with respect to pain intensity, as has been previously observed in dairy cattle following rumenocentesis (Mialon et al., 2012) or castration (Bergamasco et al., 2011). In addition, these results emphasize the lack of validity of EDA as previously cited in a bovine pain study (Baldridge et al., 2011). Interestingly, both methods indicate some chronic stress in group 1. Nevertheless, cortisol concentration and EDA measurement obtained during chronic pain were close to the values obtained at baseline. Thus, we argue that neither cortisol nor EDA is likely to be useful for assessing analgesia during acute and chronic pain states in cattle.

One limitation of the current study is that pain symptoms may be confounded with sickness behaviors of TRP, particularly decreased feeding behavior. Because of the pilot nature of this study, interpretation of pain symptoms must be considered in light of specific environmental conditions and disease pathophysiology. Therefore, it would be judicious to repeat the assessments under other housing conditions (e.g., in freestalls) and under different physiological states of the dairy cows. The main limitation of this model was the small sample size. To keep sufficient power for analysis, both the pain biomarkers and MPT measurements were averaged during the first 8-d period. This statistical method might have decreased the sensitivity of the assessment methods used during acute pain. However, it was the only method that permitted comparisons between pain biomarker levels and MPT tests, which was important in regard to the exploratory nature of studying these 2 promising pain assessment methods. The discovery of a specific and sensitive proteomic biomarker will require confirmation in other species and other pain models before innovative methods to track the neuroproteomic changes can be developed.

\section{CONCLUSIONS}

The visceral pain model activated spinal pain pathways and induced pain-related behaviors. Preemptive multimodal analgesia had a long-lasting effect, decreasing both central sensitization and pain-related behaviors, allowing us to test our hypothesis of different responsiveness (sensitivity) of methods to quantify pain. Measurements that may be affected by nonspecific stress should be analyzed with caution in pain studies. Interestingly, measurement of CSF TTR appears to have the potential to improve the sensitivity of detection of response to analgesic therapy in dairy cows suffering from chronic pain.

\section{ACKNOWLEDGMENTS}

The authors thank the Natural Science and Engineering Research Council of Canada Discovery Grant (\#327158-2008), the Canada Foundation for Innovation Ongoing New Opportunities Fund Grant (\#9483), and Vetoquinol S.A. (France) for their fellowships supporting the present work. The authors gratefully acknowledge the technical assistance of Éric Laflamme, Valerie Morin, Normand Lacasse, Guy Beauchamp, and Yaseid El Said (FMV, Université de Montréal, QC, Canada). A kind thought is addressed in memoriam to Jacques de Champlain and his laboratory team (Institut de recherches cliniques de Montréal and Department of Physiology, Université de Montréal, QC, Canada) for their support in all conducted bio-analyses.

\section{REFERENCES}

Afjehi-Sadat, L., M. Brejnikow, S. U. Kang, V. Vishwanath, N. Walder, K. Herkner, H. Redl, and G. Lubec. 2010. Differential protein levels and post-translational modifications in spinal cord injury of the rat. J. Proteome Res. 9:1591-1597.

Baldridge, S. L., J. F. Coetzee, S. S. Dritz, J. B. Reinbold, R. Gehring, J. Havel, and B. Kukanich. 2011. Pharmacokinetics and physiologic effects of intramuscularly administered xylazine hydrochlorideketamine hydrochloride-butorphanol tartrate alone or in combination with orally administered sodium salicylate on biomarkers of pain in Holstein calves following castration and dehorning. Am. J. Vet. Res. 72:1305-1317.

Bergamasco, L., J. F. Coetzee, R. Gehring, L. Murray, T. Song, and R. A. Mosher. 2011. Effect of intravenous sodium salicylate administration prior to castration on plasma cortisol and electroencephalography parameters in calves. J. Vet. Pharmacol. Ther. 34:565-576.

Borish, L., M. S. King, J. J. Mascali, S. Johnson, B. Coll, and L. J. Rosenwasser. 1992. Transthyretin is an inhibitor of monocyte and endothelial cell interleukin-1 production. Inflammation 16:471484.

Carbone, L. 2011. Pain in laboratory animals: The ethical and regulatory imperatives. PLoS ONE 6:e21578.

Chambers, J. P., A. E. Waterman, and A. Livingston. 1994. Further development of equipment to measure nociceptive thresholds in large animals. Vet. Anaesth. Analg. 21:66-72. 
Cui, Y., J. Xu, R. Dai, and L. He. 2012. The interface between inhibition of descending noradrenergic pain control pathways and negative affects in post-traumatic pain patients. Ups. J. Med. Sci. 117:293-299.

de Champlain, J., M. Karas, L. Assouline, R. Nadeau, A. R. LeBlanc, B. Dubé, and P. Larochelle. 2007. Effects of valsartan or amlodipine alone or in combination on plasma catecholamine levels at rest and during standing in hypertensive patients. J. Clin. Hypertens. (Greenwich) 9:168-178.

Edwards, J. L., and P. R. Tozer. 2004. Using activity and milk yield as predictors of fresh cow disorders. J. Dairy Sci. 87:524-531.

Fiebich, B. L., E. Candelario-Jalil, M. Mantovani, M. Heinzmann, R. S. Akundi, M. Hüll, R. Knörle, P. Schnierle, G. Finkenzeller, and B. Aicher. 2006. Modulation of catecholamine release from rat striatal slices by the fixed combination of aspirin, paracetamol and caffeine. Pharmacol. Res. 53:391-396.

Fogsgaard, K. K., C. M. Røntved, P. Sørensen, and M. S. Herskin. 2012. Sickness behavior in dairy cows during Escherichia coli mastitis. J. Dairy Sci. 95:630-638.

Fricova, J., M. Vejrazka, P. Stopka, J. Krizova, J. Belacek, and R Rokyta. 2010. The influence of pre-emptive analgesia on postoperative analgesia and its objective evaluation. Arch. Med. Sci. 6:764-771.

González, L. A., B. J. Tolkamp, M. P. Coffey, A. Ferret, and I. Kyriazakis. 2008. Changes in feeding behavior as possible indicators for the automatic monitoring of health disorders in dairy cows. J. Dairy Sci. 91:1017-1028.

Hayashida, K.-i., H. Obata, K. Nakajima, and J. C. Eisenach. 2008. Gabapentin acts within the locus coeruleus to alleviate neuropathic pain. Anesthesiology 109:1077-1084.

Heinrich, A., T. F. Duffield, K. D. Lissemore, and S. T. Millman. 2010. The effect of meloxicam on behavior and pain sensitivity of dairy calves following cautery dehorning with a local anesthetic. J. Dairy Sci. 93:2450-2457.

Herskin, M. S., L. Munksgaard, and J. Ladewig. 2004. Effects of acute stressors on nociception, adrenocortical responses and behavior of dairy cows. Physiol. Behav. 83:411-420.

Hjemdahl, P. 1988. Plasma catecholamines as markers for sympathoadrenal activity in human primary hypertension. Pharmacol. Toxicol. 63(Suppl. 1):27-31.

Huxley, J. N., and H. R. Whay. 2006. Current attitudes of cattle practitioners to pain and the use of analgesics in cattle. Vet. Rec. 159:662-668.

Huzzey, J. M., D. M. Veira, D. M. Weary, and M. A. G. von Keyserlingk. 2007. Prepartum behavior and dry matter intake identify dairy cows at risk for metritis. J. Dairy Sci. 90:3220-3233.

Ingenbleek, Y., and V. R. Young. 2002. Significance of transthyretin in protein metabolism. Clin. Chem. Lab. Med. 40:1281-1291.

Jahn, H., S. Wittke, P. Zürbig, T. J. Raedler, S. Arlt, M. Kellmann, W. Mullen, M. Eichenlaub, H. Mischak, and K. Wiedemann. 2011. Peptide fingerprinting of Alzheimer's disease in cerebrospinal fluid: Identification and prospective evaluation of new synaptic biomarkers. PLoS ONE 6:e26540.

Kemp, M. H., A. M. Nolan, P. J. Cripps, and J. L. Fitzpatrick. 2008 Animal-based measurements of the severity of mastitis in dairy cows. Vet. Rec. 163:175-179.

Krohn, C. C. 1994. Behavior of dairy-cows kept in extensive (loose housing pasture) or intensive (tie stall) environments. 3. Grooming, exploration and abnormal-behavior. Appl. Anim. Behav. Sci. 42:73-86

Krohn, C. C., and L. Munksgaard. 1993. Behavior of dairy-cows kept in extensive (loose housing pasture) or intensive (tie stall) environments. 2. Lying and lying-down behaviour. Appl. Anim. Behav. Sci. $37: 1-16$.

Kunz, S., I. Tegeder, O. Coste, C. Marian, A. Pfenninger, C. Corvey, M. Karas, G. Geisslinger, and E. Niederberger. 2005. Comparative proteomic analysis of the rat spinal cord in inflammatory and neuropathic pain models. Neurosci. Lett. 381:289-293.

Laemmli, U. K. 1970. Cleavage of structural proteins during the assembly of the head of bacteriophage T4. Nature 227:680-685.
Laven, R. A., J. N. Huxley, H. R. Whay, and K. J. Stafford. 2009. Results of a survey of attitudes of dairy veterinarians in New Zealand regarding painful procedures and conditions in cattle. N. Z. Vet. J. $57: 215-220$

Laven, R. A., K. E. Lawrence, J. F. Weston, K. R. Dowson, and K. J. Stafford. 2008. Assessment of the duration of the pain response associated with lameness in dairy cows, and the influence of treatment. N. Z. Vet. J. 56:210-217.

Malreddy, P. R., J. F. Coetzee, B. KuKanich, and R. Gehring. 2013 Pharmacokinetics and milk secretion of gabapentin and meloxicam co-administered orally in Holstein-Friesian cows. J. Vet. Pharmacol. Ther. 36:14-20.

Mialon, M. M., V. Deiss, S. Andanson, F. Anglard, M. Doreau, and I. Veissier. 2012. An assessment of the impact of rumenocentesis on pain and stress in cattle and the effect of local anaesthesia. Vet. J. 194:55-59.

Milligan, E. D., and L. R. Watkins. 2009. Pathological and protective roles of glia in chronic pain. Nat. Rev. Neurosci. 10:23-36.

Molony, V., J. E. Kent, and I. S. Robertson. 1995. Assessment of acute and chronic pain after different methods of castration of calves. Appl. Anim. Behav. Sci. 46:33-48.

Monaco, H. L. 2000. The transthyretin-retinol-binding protein complex. Biochim. Biophys. Acta 1482:65-72

Müller, R., and L. Schrader. 2003. A new method to measure behavioural activity levels in dairy cows. Appl. Anim. Behav. Sci. $83: 247-258$.

Müller, R., and L. Schrader. 2005. Individual consistency of dairy cows' activity in their home pen. J. Dairy Sci. 88:171-175.

Newby, N. C., D. L. Pearl, S. J. LeBlanc, K. E. Leslie, M. A. G. von Keyserlingk, and T. F. Duffield. 2013. The effect of administering ketoprofen on the physiology and behavior of dairy cows following surgery to correct a left displaced abomasum. J. Dairy Sci. 96:1511-1520.

Nunes, A. F., M. J. Saraiva, and M. M. Sousa. 2006. Transthyretin knockouts are a new mouse model for increased neuropeptide $\mathrm{Y}$. FASEB J. 20:166-168.

Olfert, E. D., B. M. Cross, and A. A. McWilliam. 1993. Guide to the Care and Use of Experimental Animals. Accessed Aug. 2013. http://www.ccac.ca/Documents/Standards/Guidelines/Experimental_Animals_Vol1.pdf.

Pan, W. 2001. Akaike's information criterion in generalized estimating equations. Biometrics 57:120-125.

Power, D. M., N. P. Elias, S. J. Richardson, J. Mendes, C. M. Soares, and C. R. A. Santos. 2000. Evolution of the thyroid hormone-binding protein, transthyretin. Gen. Comp. Endocrinol. 119:241-255.

Rasmussen, D. B., K. Fogsgaard, C. Rontved, I. Klaas, and M. Herskin. 2011. Changes in thermal nociceptive responses in dairy cows following experimentally induced Escherichia coli mastitis. Acta Vet. Scand. 53:32.

Remie, R., and J. Zaagsma. 1986. A new technique for the study of vascular presynaptic receptors in freely moving rats. Am. J. Physiol. 251:H463-H467.

Rialland, P., S. Authier, M. Guillot, J. R. Del Castillo, D. VeilleuxLemieux, D. Frank, D. Gauvin, and E. Troncy. 2012. Validation of orthopedic postoperative pain assessment methods for dogs: A prospective, blinded, randomized, placebo-controlled study. PLoS ONE 7:e49480.

Richardson, S. J. 2007. Cell and molecular biology of transthyretin and thyroid hormones. Pages 137-193 in International Review of Cytology. Vol. 258. W. J. Kwang, ed. Academic Press, San Diego, CA.

Richter, M. B., P. Woo, G. S. Panayi, A. Trull, A. Unger, and P. Shepherd. 1983. The effects of intravenous pulse methylprednisolone on immunological and inflammatory processes in ankylosing spondylitis. Clin. Exp. Immunol. 53:51-59.

Saito, K., M. Kanazawa, and S. Fukudo. 2002. Colorectal distention induces hippocampal noradrenaline release in rats: An in vivo microdialysis study. Brain Res. 947:146-149.

Santos, S. D., K. L. Lambertsen, B. H. Clausen, A. Akinc, R. Alvarez, B. Finsen, and M. J. Saraiva. 2010. CSF transthyretin neu- 
roprotection in a mouse model of brain ischemia. J. Neurochem. 115:1434-1444.

Schreiber, G. 2002. The evolution of transthyretin synthesis in the choroid plexus. Clin. Chem. Lab. Med. 40:1200-1210.

Stafford, K. J., and D. J. Mellor. 2005. Dehorning and disbudding distress and its alleviation in calves. Vet. J. 169:337-349.

Steen, H., and M. Mann. 2004. The abc's (and xyz's) of peptide sequencing. Nat. Rev. Mol. Cell Biol. 5:699-711.

Stilwell, G., R. C. Carvalho, N. Carolino, M. S. Lima, and D. M. Broom. 2010. Effect of hot-iron disbudding on behaviour and plasma cortisol of calves sedated with xylazine. Res. Vet. Sci. 88:188-193.

Strohalm, M., M. Hassman, B. Košata, and M. Kodíček. 2008. mMass data miner: An open source alternative for mass spectrometric data analysis. Rapid Commun. Mass Spectrom. 22:905-908.

Theurer, M. E., B. J. White, J. F. Coetzee, L. N. Edwards, R. A. Mosher, and C. A. Cull. 2012. Assessment of behavioral changes associated with oral meloxicam administration at time of dehorning in calves using a remote triangulation device and accelerometers. BMC Vet. Res. 8:48
Tsigos, C., and G. P. Chrousos. 2002. Hypothalamic-pituitary-adrenal axis, neuroendocrine factors and stress. J. Psychosom. Res. $53: 865-871$.

Urton, G., M. A. G. von Keyserlingk, and D. M. Weary. 2005. Feeding behavior identifies dairy cows at risk for metritis. J. Dairy Sci. $88: 2843-2849$

Walker, K. A., T. F. Duffield, and D. M. Weary. 2011. Identifying and preventing pain during and after surgery in farm animals. Appl Anim. Behav. Sci. 135:259-265.

Whay, H. R., A. E. Waterman, A. J. Webster, and J. K. O'Brien. 1998. The influence of lesion type on the duration of hyperalgesia associated with hindlimb lameness in dairy cattle. Vet. J. 156:23-29.

White, B. J., J. F. Coetzee, D. G. Renter, A. H. Babcock, D. U. Thomson, and D. Andresen. 2008. Evaluation of two-dimensional accelerometers to monitor behavior of beef calves after castration. Am. J. Vet. Res. 69:1005-1012.

Ziegler, A., C. Kastner, and M. Blettner. 1998. The generalised estimating equations: An annotated bibliography. Biom. J. 40:115139 
APPENDIX

Table A1. Veterinarian pain scale (VPS) ${ }^{1}$ used in this cow study

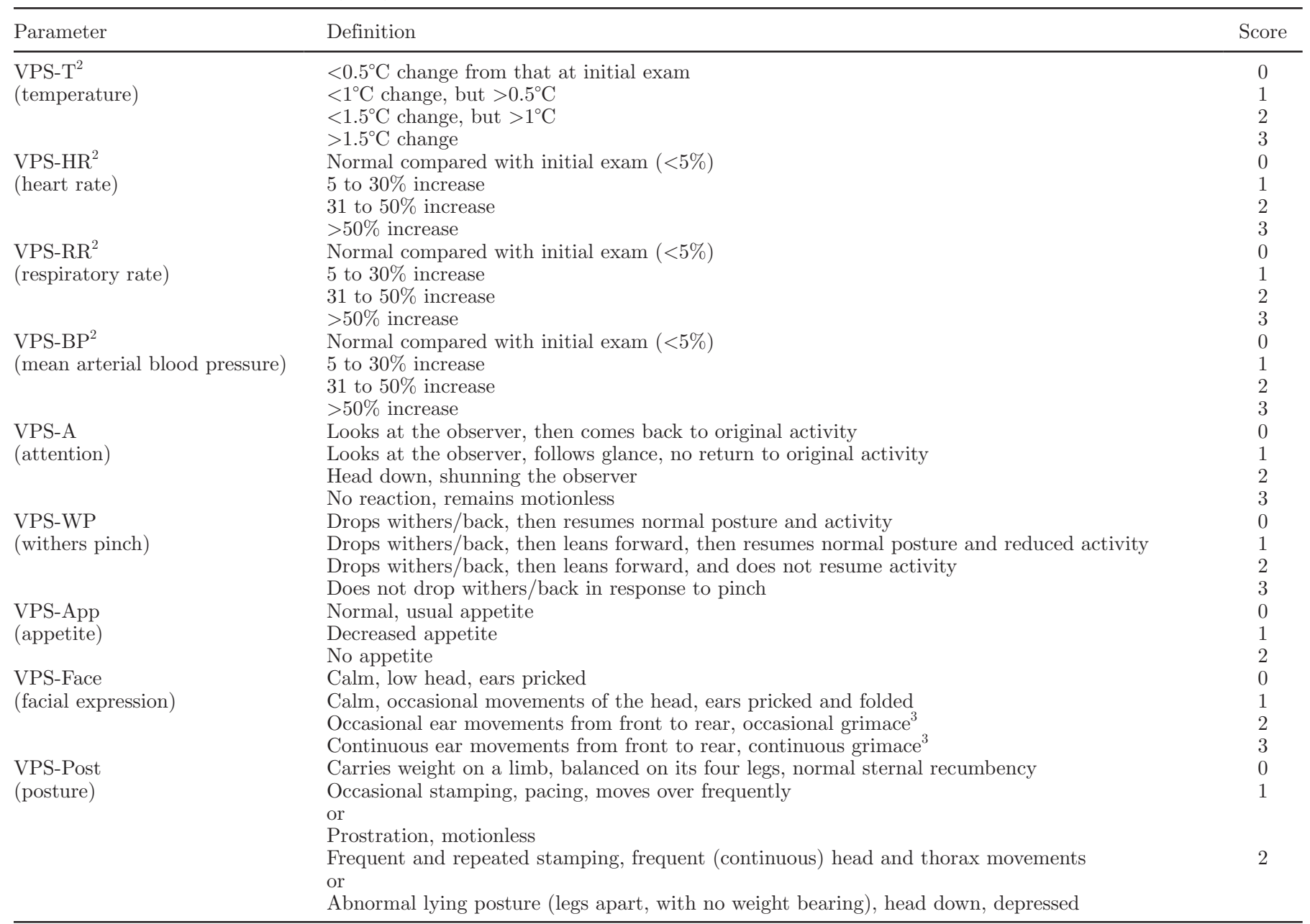

${ }^{1}$ The VPS was constructed with parameters relating to physiological changes based on temperature (VPS-T), heart rate (VPS-HR), respiratory rate (VPS-RR), and mean arterial blood pressure recording (VPS-BP), interactive behavior [attention (VPS-A) and response to withers pinch (VPS-WP)], and well-being [appetite (VPS-App), facial expression (VPS-Face), and posture (VPS-Post)].

${ }^{2}$ Physiologic changes were scored according to the percentage of change compared with values obtained at $d-7$.

${ }^{3}$ Nose movements, eyebrow movements, rictus, wince.

Table A2. Technician pain scale used in this cow study

\begin{tabular}{lcc}
\hline Item & Present & Absent \\
\hline Not approaching food & 1 & 0 \\
Not eating & 1 & 0 \\
Not ruminating & 1 & 0 \\
Abnormal posture & 1 & 0 \\
Unusual behavior when close to the observer & 1 & 0 \\
Fear or avoidance & 1 & 0 \\
Vocalization or teeth grinding & 1 & 0 \\
Aggressiveness & 1 & 0 \\
Total score $^{1}$ & 8 & \\
\hline
\end{tabular}

${ }^{1}$ Technician pain scale scores ranged from 0 (no pain) to 8 (severe pain). 